\title{
Libros de fiscal, libros de oidor: la biblioteca de Domingo de Arangoiti (siglo XVIII)
}

\author{
Idalia García *
}

Artículo recibido:

19 enero de 2012.

Artículo aceptado:

11 de mayo de 2012.

\section{RESUMEN}

La historia de las bibliotecas novohispanas parece ser un tema ampliamente investigado. Lo cierto es que este territorio de conocimiento es un gran desconocido pese al interés que ha tenido para diferentes disciplinas. En gran parte tal situación se puede explicar por la escasa atención que han tenido los documentos conservados. Éstos testimonian el número y tipo de material que conformaron esas colecciones bibliográficas. Entre estas bibliotecas las más olvidadas son las particulares y, al igual que otras, su estudio permite comprender las características de la cultura escrita de un periodo histórico. También son documentos que contribuyen a valorar nuestro legado bibliográfico. En

* Instituto de Investigaciones Bibliotecológicas y de la Información de la UNAM, México.pulga@iibi.unam.mx

INVESTIGACIÓN BiBLIOTECOLÓGICA, Vol. 26, Núm. 57, mayo/agosto, 2012, México, ISSN: 0187-358X. pp. 13-76 
este texto se presenta el caso de una biblioteca virreinal para mostrar la complejidad de la fuente histórica así como las enormes posibilidades de información que podemos obtener de estos testimonios.

Palabras clave: Historia de las bibliotecas; Bibliotecas Particulares; Bibliotecas Novohispanas; Cultura Escrita.

\begin{abstract}
Prosecutors and Judges books: The personal library of Domingo de Arangoiti (18th century)

Idalia García

The history of Libraries in New Spain seems to be an extensively researched topic. Actually this field of knowledge is still largely unknown despite the interest of different disciplines. This situation can be explained mostly by the lack of attention that historical evidence has generally had. These books witness the number and type of material conforming those book collections. Among these libraries the most forgotten are personal collections, but their study allows to fully understand the characteristics of written culture in the past. They also are documents which contribute to appreciate our bibliographical legacy. In this paper, we explain through one colonial library the complexity of historical sources and the enormous possibilities of information that we can extract from these testimonies.
\end{abstract}

Keywords: History of Libraries; Personal Libraries; Libraries in New Spain, Written culture. 
A lo menos no puede dudarse, que la Ciencia sea muy util a un hombre de calidad, como sepa usar bien de ella, y que en lugar de ensobervecerse a su saber le sirva para arreglar su coraçon, y perficionar su entendimiento

VALERIO DE BorXa y LoAiso (I727)

n algunas casas de la Nueva España además de muebles, pinturas, tapi-
ces y otros objetos producidos en diferentes partes del mundo, también se encontraban libros. Sin duda de este periodo de nuestra historia no podemos tener plena certeza del número de personas que adquirían libros ni tampoco las razones que los inspiraban a esto. Podríamos decir que los libros se compran porque van a ser leídos, pero la historia nos ha mostrado que hubo otro tipo de usos para los libros que no tenían nada que ver con la función para la que fueron diseñados.

Lo que sí sabemos es que en nuestros archivos y bibliotecas existe un número desconocido de testimonios documentales y bibliográficos que conforman un territorio ignoto por dos razones principales. La primera, es que en nuestro país no ha sido prioridad el registro de todos esos objetos conservados. En consecuencia constituyen un caudal de fuentes, que no pueden aprovecharse en su forma original ni tampoco justificar un proyecto que favorezca su acceso digital. La segunda razón es todavía más triste, porque esa abundancia no parece ser del interés de la investigación que prefiere el empleo de fuentes secundarias para realizar interpretaciones históricas de la cultura escrita de los novohispanos. Por fortuna siempre existen excelentes y puntuales casos que reconfortan (García 2010) todas las preocupaciones antiguas y modernas.

Ahora bien, entre todos los documentos coloniales que podrían ayudar a comprender ese pequeño espacio de un lector y sus libros, existe uno que ya ha sido distinguido en varias investigaciones internacionales desde la década de los setenta del siglo pasado. En especial aquéllas que giran en torno a la temática de las bibliotecas del pasado. Nos referimos al denominado como inventario post mortem que se ha consolidado como el documento predominante para la investigación sobre los libros de una época, pese a las dificultades que enfrenta su análisis (Dadson 2008, 253). Este tipo de documento se conserva en muchos países en los archivos notariales. México no es la excepción pero, por razones administrativas e históricas, algunos de estos documentos se conservan actualmente en el Archivo General de la Nación.

Tal inventario fue crucial para posibilitar la transmisión patrimonial entre familias y generaciones, solía realizarse prácticamente por todos aquellos 
que tenían una o varias posesiones y deudas que heredar. Por esta condición lo realizaron quienes podían, pues se trata de una escritura notarial por la que se debe pagar ante un escribano público y, por lo cual, como testimonios no poseen una amplia representatividad social. Los inventarios post mortem son recuentos de objetos de la más diversa naturaleza, pero "pueden presentar peculiaridades propias en el tipo de información que incluyen y en su grado de minuciosidad, dependiendo del área geográfica en la que se llevan a cabo" (Sobrado 2003, 832).

Este es el caso de la Nueva España, pues este inventario se realizó en todas las ciudades por quienes así lo requerían, ya fuese por el tipo de bienes que se registran o por el tipo de objetos que se encuentran en cada espacio de la vivienda. El inventario es "una escritura que se haze de los bienes del difunto y tiene obligacion à hacerlo por ante Escrivano el heredero en testamento" (Ripia 1718, 170). De ahí que se les denomine post mortem. Pero en algunos territorios, como los americanos y por el tipo de población que había, estos inventarios no solamente se realizaron ante un escribano público sino que también se incluyeron en los trámites que fueron realizados para asegurar la entrega de los bienes de los fallecidos en Indias. Condición que era necesaria siempre que estos fueran peninsulares y extranjeros, y cuyos herederos viviesen en territorio español o europeo. Este es el asunto al que se dedicó el Juzgado de Bienes de Difuntos de cada audiencia americana, como lo establecía una profusa y complicada legislación que se fue elaborando desde el siglo XVI.

En los expedientes de Bienes de Difuntos que se conservan completos se pueden encontrar los siguientes documentos: testamento, inventario, almoneda, resolución de cuentas, fe de registro, carta de diligencia, informaciones, probanzas y acta de entrega (Pelegrí 2003, 18). Como se aprecia, se trata de un conjunto de expedientes que permiten obtener mucha información sobre diversos aspectos de la vida cotidiana, social y económica de las personas. Esta es una de las peculiaridades sustanciales que diferencia al inventario de Bienes de Difuntos del otro realizado ante cualquier escribano. Aunque en ambos casos se trata de inventarios post mortem.

Por su parte, en los inventarios realizados ante escribano suelen encontrarse omisiones importantes como ciertos datos personales (lugar de nacimiento o número y nombre de los hijos), puesto que pueden interpretarse más correctamente con la información que contenía el correspondiente testamento. Este documento, que expresa las últimas disposiciones de una persona que deben cumplirse a su muerte (López 1798, 15), se elaboraba como hemos precisado antes del inventario integrando además cláusulas religiosas y morales características de su época. El testamento fue considerado como 
tarea ineludible que debía realizar todo buen cristiano antes de morir, pero sólo podían hacerlo aquellos que estaban sanos y en buen juicio.

Lamentablemente esos testamentos antiguos no siempre se conservan en los archivos notariales con el inventario que les corresponde. En la mayoría de los casos, sólo se puede encontrar el inventario o el testamento. De forma tal que cuando se halla solamente un inventario de bienes, no siempre se pueden conocer muchos datos personales y familiares de ese difunto. Por el contrario, en la documentación de Bienes de Difuntos es más frecuente encontrar testamentos e inventarios juntos aunque estos expedientes se hayan conservados en otro tipo de repositorio que no necesariamente es el correspondiente a los de notarías.

Este es el caso que queremos aquí presentar. Un expediente de Bienes de Difuntos que contiene la relación de libros poseídos por una persona puesto que se hizo al paralelo de todos los objetos, y por tanto es un inventario que registra todas las posesiones de acuerdo a su tipo y, entre éstas, a los libros. Al conservarse prácticamente completo dicho expediente, nos podremos acercar a varios detalles de la vida de este personaje. Sin embargo aquí nos interesa analizar los libros de la librería particular, nombre antiguo que se daba a las bibliotecas, porque se trata de la colección de un funcionario colonial que trabajó en dos audiencias de la Nueva España. Nos referimos a Domingo de Arangoiti, vasco migrante del siglo XVIII.

\section{De LA VIDA Y MUERTE DEL SEÑOR Arangoiti}

Como se sabe, en algunos casos afortunados podemos tener noticias sobre la vida de un personaje del pasado gracias a que se conserva documentación histórica relacionada con éste. Tal es el caso de Domingo de Arangoyti Peña, de quien se resguarda su auto de difuntos en el Archivo General de la $\mathrm{Na}$ ción en México, ${ }^{1}$ debido a que fue español sin herederos en la Nueva España. Por eso sus bienes quedaron bajo la tutela del citado Juzgado de Bienes de Difuntos, tal y como lo establecían las Leyes de Indias. También tenemos la fortuna de contar con dos expedientes más de este personaje, que nos aportan mayores datos personales y que se encuentran custodiados en el Archivo

1 "Autos fechos de pedimento del Señor Don Miguel Calixto de Acedo del Consejo de su Magestad su Oydor en esta Real Audiencia sobre que se declaren por Inventarios Jurídicos del Señor Domingo Arangoiti del mismo Consejo las memorias qye presenta" Archivo General de la Nación (en adelante AGN), Intestados, Vol. 48, exp. 2, fol. 307r.-406r. 
General de Indias en Sevilla (España). Se trata de su Relación de Méritos de 1756 y la Licencia de Pasajeros que tramitó en $1764 .^{2}$

Con estos documentos podemos saber que Domingo de Arangoyti o Arangoiti (con ambas formas en los documentos) fue hijo legítimo de Casimiro Arangoyti y de María de la Peña. También que fue natural de Lezama en el Valle de Ayala en la Provincia de Álava en el Reino de Castilla ${ }^{3}$ y que viajó al territorio americano con nombramiento de fiscal de la Real Audiencia de Guadalajara en la provincia de la Nueva Galicia, a partir del 17 de marzo de 1764. ${ }^{4}$ Aparentemente estuvo en este territorio hacia 1773 (Torales 2001, 255) o 1776, cuando se trasladó a la Audiencia de México para sustituir a Joseph Antonio de Areche quien fue enviado a Perú como visitador general por orden del Rey Carlos III (Bass 2008, 52; Gates 1928, 14). Por su parte Arnold $(1980,17)$ lo ubica como Fiscal del Crimen de Real Hacienda y de Real Audiencia entre 1775 y 1776, así como ejerciendo el cargo de Oidor de la Real Audiencia entre 1777 y 1779.

En esta Real Audiencia de México llegó a ser el Oidor más antiguo, cargo que ostentaba a la fecha de su muerte en la ciudad de Querétaro en $1780 .^{5}$ Sabemos que Arangoiti trabajó tanto en la Audiencia de Guadalajara como en la de México (Borah 1983, 80; Brading, 1983, 68). Lo cual no debería resultar extraño pues la carrera judicial de un magistrado solía iniciarse en audiencias intermedias como la de Guadalajara, pero buscando ascender hacia una plaza en una ciudad más importante como la Audiencia de México. Una movilidad geográfica y laboral que no estuvo exenta de denuncias por abusos cometidos con las plazas. (Sanciñena 1999, 38 y 93). Como podemos ver el gusto por su plaza a Domingo de Arangoiti le duró muy pocos años.

Arangoiti pudo acceder a tales cargos porque poseía una sólida formación que había obtenido en la Universidad de Alcalá durante quince años.

2 El primer documento en Archivo General de Indias (en adelante AGI), Indiferente 156, N.19, 4 imágenes; segundo también en AGI, Contratación 5507, N.1, R.4, 44 imágenes. La consulta de ambos está disponible en el Portal de Archivos Españoles PARES (https://pares.mcu.es). Es importante mencionar que en esta base de datos las imágenes correspondientes a la licencia de pasajeros de Arangoiti se encuentran vinculadas al registro de la licencia de pasajeros de Miguel Calixto de Acedo. Ahí mismo se encuentran las correspondientes a éste, quien viajó con nombramiento de Oidor de la Real Audiencia de Santo Domingo en 1764, el mismo año del viaje de Arangoiti. Calixto de Acedo es también la persona que tramitó el auto de Bienes de Difuntos de Arangoiti en 1780. En la signatura que PARES reporta debe encontrarse la información de Arangoiti, se encuentra asimismo la de Cosme Damián de Ugarte, quien viajó como Alcalde Mayor de Yzucar (en el estado de Puebla) también en 1764.

3 “Testamento". AGN, Intestados, Vol. 48, exp. 2, fol. 308r.

4 El 6 de noviembre de 1766, el virrey informa que ha pasado a Domingo de Arangoti "que se halla en esta ciudad, dando principio a la residencia de mi antecesor". AGN, Correspondencia de Virreyes, vol. 11, núm 75, fol. 149r.

5 Torales indica que su muerte fue en 1781, pero por su expediente de Difuntos sabemos que fue un año antes. 
Todavía no hemos encontrado noticia de su fecha de nacimiento, es un dato que no ha podido ser localizado (Burkholder y Chandler 1982, 21-22), sólo sabemos que ingresó a la Universidad en 1741, y que obtuvo el grado de bachiller en 1746 y el de licenciado en 1753. Ambos grados fueron en Cánones, ${ }^{6}$ y también Arangoiti concluyó los estudios de Licenciado en Leyes igualmente en este último año, por lo que era opositor a las Cátedras de esa misma Universidad. También tenemos noticia de que Arangoiti había quedado en tercer lugar en 1757 para la plaza de Oidor de Guatemala, que en 1761 quedó en tercer lugar para la correspondiente a la Fiscalía de la Audiencia de Santo Domingo y también que obtuvo el segundo lugar para el puesto de la Fiscalía Criminal de la Audiencia de México. Está visto que Arangoiti buscaba afanosamente una plaza de funcionario en el territorio americano y no en otro, fructificando sus esfuerzos hasta $1764 .^{7}$

Tenemos noticias de otras actividades profesionales de Arangoiti. Por ejemplo, que fue Fiscal de la Real Hacienda en 1777 cuando el Virrey Bucareli le solicitó la elaboración de un informe sobre la Real Orden de 12 de enero del mismo año que instaba al cultivo del lino y del cáñamo en el territorio novohispano (Serrera 1974, 81). Este tipo de fiscal era un abogado que se agregaba a una audiencia en donde se ocupaba de los asuntos fiscales (Brading 1983, 13). Diecinueve años más tarde, en 1796, los resultados del informe se publicaron por Mariano de Zúñiga y Ontiveros ${ }^{8}$ con el título Instruccion para sembrar, cultivar y beneficiar el lino y cañamo en la Nueva Espa$\tilde{n} a$ (Serrera 1974, 96 y 262). Este impreso es una singular noticia que tenemos de obras de autoría de Arangoiti, cuyo único ejemplar conservado parece ser el que se custodia en el Archivo General de Indias (Medina 1989, VIII, 55).9 Otra obra aunque de tipo compilatorio será el manuscrito que aparentemente estaba preparando y que se encontró en su biblioteca (279). Decimos esto porque según los datos se trata de una recopilación de normas y su índice, que solían elaborar los abogados por su utilidad y porque formaba parte de un sistema ordenador que reflejaba la lógica de la burocracia y la jurisdicción (Wanderley 2000,5).

Después de todo ese esfuerzo, el oidor murió soltero pese a que en 1766 había obtenido permiso para casarse con una natural de la Nueva España

6 AGI, Indiferente 156, N.19, imagen 1.

7 Viaje que realizó acompañado de los criados, Felipe Fernández de Valderrama de 20 años y Domingo Miguel de Unzueta de 23. Ídem.

8 Para conocer el trabajo de este impresor y de su padre Felipe, más conocido, es recomendable consultar el trabajo de Manuel Suárez Rivera, Felipe y Mariano de Zúñiga y Ontiveros: impresores ilustrados y empresarios culturales (1761-1825). Tesis de Licenciatura en Historia. UNAM. Facultad de Filosofía y Letras, presentada en noviembre de 2005.

9 Aunque Medina no menciona esta autoría en el registro 8598, por el contrario se la reconoce al Marqués de Branciforte, cuyo nombre aparece en portada. 
(Burkholder y Chandler 1982, 22). Por lo visto fue una persona muy responsable, pues inmediatamente después de su protesta de fe, encomendar su alma y expresar los deseos sobre su funeral y entierro, dedica en el testamento su atención a los expedientes que tiene bajo su custodia como funcionario virreinal. Así, determinó que a cargo de los papeles se quedase el receptor Antonio Córdoba, hasta que el Virrey tomara la resolución pertinente. ${ }^{10} \mathrm{Su}$ primer albacea testamentario fue Miguel Calixto de Acedo, del Consejo de su Majestad y Oidor de la Real Audiencia de México donde también laboraba Arangoiti; ${ }^{11}$ el segundo albacea fue el padre Diego Marín de Moya, de la orden de los Agonizantes de la Ciudad de México y Comisario General de la Casa de San Camilo de Lelis. Fue nombrado como heredero universal de los bienes del funcionario el Ujier de Cámara Juan Manuel Arangoiti, primo del difunto y residente en Madrid. ${ }^{12}$

El testamento fue fechado el 31 de enero de 1780, y Arangoiti moriría ocho días después, como consta en la notificación de su fallecimiento dada en Santiago de Querétaro, lugar donde residía nuestro personaje. ${ }^{13}$ Tuvo por testigos al presbítero y abogado Antonio Ramón Canaliro, Antonio Ecala, comerciante, y Francisco Vallejo Mandujano. El testamento fue realizado por el escribano real y público Joseph Ignacio de Vera. Arangoiti deseaba ser sepultado en la Iglesia del Colegio Apostólico de la Santísima Cruz de Milagros de la Ciudad de Querétaro, a cuyos religiosos dejó cien pesos para las misas por su alma. ${ }^{14}$ La misma cantidad que dejó para su criado Mateo de Bargae por su "legalidad y buen servicio" y que debían ser entregados en reales. También debían entregarse a María Antonia, la cocinera, treinta pesos, y a su marido cuarenta, cuyo nombre no recordaba y cuya razón no se menciona. Finalmente al cochero debían entregársele treinta pesos, ${ }^{15}$ así como ordenó que se pagasen todas sus deudas.

Los bienes que nuestro personaje reconocía estaban conformados por todas las alhajas y propiedades que tuviera en Querétaro, su residencia habitual, así como todas aquellas que declarase de su propiedad el padre Marín de Moya a quien hemos mencionado como segundo albacea. Dichos bienes

10 AGN, Intestados, Vol. 48, exp. 2, fol. 310r.

11 Puede ser una coincidencia, pero es el nombre de la misma persona que viajó en el mismo año que Arangoiti con nombramiento de Oidor de Santo Domingo. El tipo de cargo no parece dejar a dudas de que ambos se conocieron antes de viajar a América.

12 "Criado del rey, que asistía en la antecámara para cuidar de la puerta y de que solo entrasen las personas que debían entrar, por sus oficios u otros motivos". Diccionario de la Real Academia Española. Consulta disponible en http://www.rae.es [Consulta: septiembre de 2011]

13 AGN, Ayuntamientos 78, vol. 224, expediente sin especificar.

14 Lo cierto es que lo religiosos tan sólo recibieron cincuenta pesos. AGN, Intestados, Vol. 48, exp. 2 , fol. $311 \mathrm{v}$.

15 Ibídem, fol.387r. 
debían ser agrupados por el comerciante Tomás de Ecala, para que una vez vendidos se costearan los gastos del funeral, sus disposiciones y se entregase su herencia. Los albaceas testamentarios tuvieron poder, derecho y facultad para vender y rematar los bienes de Arangoiti en una almoneda. Asunto al que se dedicaron una vez que obtuvieron el poder del heredero universal y primo del difunto. Miguel Calixto se hizo responsable de los inventarios y almonedas, mientras que el padre Diego de la administración del dinero.

Tres años después de la muerte del oidor, se recuperaron de sus bienes 15,000 pesos en plata doble que fueron enviados como su herencia a España. El dinero fue dividido en tres partes y entregado a Felipe Montes, maestre del navío San Felipe el 7 de octubre; Juan José Larrio, maestre del navío El Septentrión el 13 de octubre; y por último a Francisco Páez, maestre del Navío Santo Domingo el 16 de octubre. ${ }^{16}$ Finalmente el expediente de Arangoiti fue cerrado el 7 de noviembre de 1783 por el defensor de Difuntos, Manuel Joaquín Hidalgo en la Ciudad de México

El inventario y avalúo de los bienes de Arangoiti ${ }^{17}$ inicia con la carpintería que registra y avalúa Santiago Mariano Romero. Después las guarniciones por Pedro Cuadros, la platería por Pedro de Ávila, la ropa hecha por Francisco Augusto, la ropa sin hacer por Joaquín Martín de Lasso, las pinturas por Joseph Mendoza, y otros varios bienes por Joaquín de Ugalde y por Joseph Manuel Corona. Al final dos cupés ${ }^{18}$ fueron tasados por Francisco Xavier Guerrero. Los bienes parecen haberse vendido en su gran mayoría en las almonedas como bien lo certificó Miguel Calixto de Acevedo. ${ }^{19}$

La librería fue inventariada y valuada aparte de los otros bienes por $\mathrm{Ma}$ nuel Cueto, trabajo por el que cobró trece pesos en julio de $1780 .{ }^{20} \mathrm{La}$ misma cantidad que se le pagó a Ignacio Quesada por copiar en limpio el inventario de todos los bienes en noviembre del mismo año. También trece pesos y tres reales se pagaron para quitar vidrieras, el armazón de la despensa, y mudar la librería. Aunque de Cueto sabemos muy poco, lo cierto es que lo hemos encontrado como valuador de varias bibliotecas privadas del siglo XVIII, además podemos suponer que fue un librero experimentado en el mercado del libro

16 Ibidem, fol. 321r.-324r.

17 "Reconocimiento, Memorias, y Abaluos de los Bienes que quedaron por muerte del Señor don Domingo Arangoiti del Consejo [su Magestad] y su Oydor en esta Real Audiencia de Mexico. El qual falleciò en la Ciudad de Querétaro a 8 de Febrero del Año de 1780". Ibídem, fol. $327 \mathrm{r}$.

18 "Coche de caballos cerrado, de dos asientos comúnmente". Diccionario de la Real Academia Española. Consulta disponible en http://www.rae.es [Consulta: septiembre de 2011]

19 AGN, Intestados, Vol. 48, exp. 2, fol. 339v.

20 Ibidem, fol. 381r. 
usado en la Ciudad de México ${ }^{21}$ puesto que encontramos noticia de su librería ante la inquisición novohispana. ${ }^{22}$

Sin duda la vida de Domingo de Arangoiti es tan interesante como la de cualquier funcionario del Virreinato. Especialmente porque fue convocado por el Virrey para analizar y expresar opiniones sobre asuntos importantes que afectaban o podrían afectar a la Colonia. Ya hemos visto que su informe sobre la producción de lino y cáñamo fue publicado después de su muerte, pero también el mismo virrey Bucareli le solicitó su opinión y dictamen para la regulación sobre los Montepíos en la Nueva España (Chandler 1991, 56). Es seguro que reconstruir una vida del pasado como la de Arangoiti nos permitirá diferenciar a sus homónimos de la misma época o precisar las fechas de los asuntos jurídicos en los que efectivamente participó este originario de Lezama. ${ }^{23}$ Pero no es esta nuestra intención, sino solamente mostrar el tipo de libros que conformaron la biblioteca privada del oidor Arangoiti a través de la transcripción de la memoria de sus libros.

\section{UNA BIBLIOTECA DE FINALES DEL SIGLO XVIII}

El inventario de los libros de Arangoiti contiene el registro de 442 títulos en 902 volúmenes, que fueron valuados en 1,184 pesos y 7 reales. ${ }^{24}$ Una cantidad que resulta muy inferior a los 15,000 pesos que se obtuvieron del resto de los bienes. El inventario fue organizado por el formato de los libros: folio, cuarto y octavo. La venta de estos fue medianamente buena como también lo informó el albacea Calixto de Acedo, aunque el documento no dice nada sobre los compradores de esos libros. ${ }^{25}$ De esos 443 títulos, se vendieron tan sólo 191 libros en lo que suponemos fue la primera almoneda, pues después se informó que aún quedaban 253 libros. Sin embargo, en este expediente y en nuestra búsqueda documental no hemos encontrado mayor información para determinar si hubo más almonedas posteriores o algún otro tipo de venta de las posesiones. Lo cierto es que podríamos suponer que no existió mayor problema con este trámite porque así lo indica el cierre del expediente ante el Juzgado de Difuntos y el envío del dinero a la península.

21 Lo suponemos porque la firma que emplea y valida el expediente de Domingo de Arangoiti es la misma de los otros documentos localizados.

22 AGN. Inquisición 1100, fol. 283 r.

23 Hemos localizado cuando menos dos Domingos de Arangoiti en fechas coincidentes con este oidor, en Madrid y en Nueva España, pero cuyos datos no permiten establecer que se trata de una sola persona. 
El inventario de la biblioteca de Arangoiti es un documento que ofrece información valiosísima porque el valuador tuvo el cuidado de indicar autores, títulos, lugares y años de edición. Un caudal de datos que no suele ser común en este tipo de documentos, puesto que la gran mayoría enlistan brevemente los títulos de las obras y los autores, o simplemente los autores o las obras. Una costumbre o forma de registro que suele ser mencionada como una dificultad por quienes han trabajado tan particulares fuentes (Fernández 1999-2000, 102), a la que se añade que en ocasiones los autores y títulos pueden ser castellanizados o también latinizados, lo que dificulta su correcta identificación.

Tal práctica, que se refleja en los documentos, no puede ser siempre y obligatoriamente atribuida a una carencia de cultura escrita de quienes hicieron estos testimonios. Por el contrario debemos pensar que para hacer inventarios y tasaciones se suele encargar a alguien que, o bien conoce el producto bibliográfico o tiene un cierto nivel de cultura y, desde luego, sabe cuánto cuestan los libros en el mercado. Cuestión que podemos apreciar bien en este inventario, ya que se registran varios libros sin portadas (llamadas carátulas), pero tal condición no impide que el valuador reconozca las obras como puede verse en el registro (360), por citar uno de estos casos. Sin duda nos encontramos frente a una documentación que no fue hecha para facilitarnos o entorpecernos el trabajo, sino con una finalidad administrativa. La comparación entre cierto tipo de inventarios o memorias de una época específica nos ayudarán a entender ciertas tendencias que son representaciones culturales de una época y de un medio profesional. De ahí la importancia de presentar estos testimonios.

La metodología para el análisis de estos documentos puede parecer complicada y engorrosa, lo cierto es que siempre es necesario hacer precisiones de una tarea que es ante todo laboriosa (Lamarca 1994, 17). Pero antes es ineludible preguntar sobre la pertinencia de este tipo de estudios, y si los datos compilados y analizados aportarán algo nuevo sobre las bibliotecas del pasado. En el caso de las bibliotecas particulares del periodo novohispano nos parece que sí porque siguen siendo territorios ignotos de conocimiento. Por tal razón han sido sujetas de innumerables interpretaciones y valoraciones, muchas de ellas bastante equivocadas (Torre 1962, 6). En efecto, el estudio de los inventarios de estas bibliotecas es tan sólo una de las estrategias conocidas (Huarte 1955, 556-560) para acercarnos a un momento cultural del pasado, conocimiento que nos permite valorar mejor el legado bibliográfico de una sociedad.

Ahora bien, la cuestión metodológica a la que nos enfrentamos muestra una enorme variedad de tendencias desde diversas disciplinas y latitudes, lo 
que da una idea del enorme problema que representa. Este espacio no permite ahondar en dicha problemática, ${ }^{26}$ por lo que sobre este punto sólo haremos breves indicaciones. Una de éstas es necesario apuntarla, aunque parezca evidente, porque tiene que ver con la elección de presentar y analizar los datos recuperados de forma general o de forma específica. En tal decisión sin duda influirá la forma en que los datos fueron registrados en el documento original que, como se ha podido constatar, podrían separarse entre los testimonios que poseen mayores datos para la identificación, como las ciudades y años de impresión, y aquellos que no los poseen, como relaciones de autores, títulos o la mezcla abreviada de ambos.

Las relaciones más completas facilitan con mayor precisión la identificación de la mayoría de las ediciones registradas que formaron parte de una biblioteca antigua. Con las otras relaciones resulta más complejo el trabajo de identificación, porque lo cierto es que nunca sabremos con total certeza cuál fue la edición que se registró de todas las producidas, salvo en los casos en que estas fueron únicas. Por ejemplo: "Caprisolato. Decisiones en Ginebra 1706” es un dato que facilita la identificación de una edición específica, mientras que "Flos Sanctorum" es un registro que abre un enorme espacio de posibilidades pues representa el título de un tipo de obra ampliamente publicada. De ahí que para este tipo de testimonios parcos o poco informativos, algunos autores recomiendan (Dadson 2008, 32) que lo más sensato y común sea identificar la primera de las ediciones conocidas, pues es la que estaría sujeta de reediciones y reimpresiones aunque sea con las variaciones textuales que posibilitó la prensa manual.

La tendencia en la mayor parte de los estudios sobre bibliotecas novohispanas se realiza de forma general, tanto en la presentación como en el análisis de los datos. De ahí que sean escasos los precedentes que nos ayuden a identificar ediciones concretas. Veamos un caso que muestra cómo de haberse identificado previamente una obra con mayor precisión, ahora sería más fácil disponer de un dato concreto: en la Biblioteca del Doctor Hinojosa se registró el libro "Cautelas, de Sepola, duplicadas" (Ramírez 2002, 335), ${ }^{27}$ es posible que este autor sea el mismo que corresponde al registro Sepola (435) de los libros de Arangoiti que hemos podido identificar como Bartolomeo Cipolla (o Cepolla),

26 Cuestión que forma parte nodal del trabajo de la investigación que actualmente desarrollo y que se titula "Representaciones culturales del impreso: fuentes originales para el conocimiento histórico de libros y bibliotecas en la Nueva España, siglos XVII y XVIII".

27 Es posible que se trate de una de las ediciones de esta obra: Tractatus cautelarum auctoribus atque collectoribus infra scriptis, Bartolomaeo Caepolla Veronense, Thoma Ferratio de Aduocatis ... Cum praefatione, De recto atque vero cautelarum vsu, et earundem vtilitate, clariss. I.C. Ioannis Fichardi Francofurtensis... Francofurti : ex officina typographica Nicolai Bassaei, 1575 (CCPB000026752-X). 
pues en este inventario se registró un tratado sobre la esclavitud. Este es un mero ejemplo de lo poco que avanzamos en el terreno de la identificación precisa de los libros de las bibliotecas particulares en la Nueva España. Situación actual que podría resolverse creando una herramienta de consulta que agrupe, sistematice y relacione los registros de estas bibliotecas.

La propensión de otras latitudes sobre el trabajo con estos inventarios librescos posibilitó la publicación de numerosos testimonios de bibliotecas antiguas que actualmente son un basamento imprescindible para acercarnos a su historia. De ahí la importancia de publicarlos, pues nos ayudarán a definir mejor el panorama de la cultura escrita de los novohispanos. Sin duda se trata de textos engorrosos pero enormemente útiles en tanto no contemos con un instrumento integral, pues una biblioteca hace la suma de varias y así subsecuentemente.

Por otro lado, la identificación de los libros registrados en el pasado se realiza directamente con los catálogos colectivos o particulares que registran el patrimonio bibliográfico conservado en un país o en una institución. La recuperación de la información siempre estará determinada por el tipo de datos que estos instrumentos registran y especialmente por las posibilidades de búsqueda que ofrecen. Herramientas que precisamente por estas características se han ganado la confianza de los investigadores por su fiabilidad, tal es el caso del Catálogo Colectivo del Patrimonio Bibliográfico Español, el Catalogo del Servizio Bibliotecario Nazionale (Italia), o HeBi Retro, ${ }^{28}$ entre otros. También se emplean repertorios bibliográficos antiguos como el de Nicolás Antonio, u otros distintos más contemporáneos pero que son igualmente útiles como el de Palau y Dulcet o catálogos publicados de colecciones universitarias. Tampoco debe descartarse la utilidad que tienen para esta tarea otros inventarios de la misma época publicados, en los cuales podremos encontrar rastros y pistas de autores u obras del pasado.

Desde esta perspectiva no debemos olvidar que los datos de los libros que disponemos no son tan precisos como suponemos, sino que responden a una época cultural muy distinta a la nuestra. En ocasiones la forma del registro lo facilita como Blas Altimaro para Biagio Altimori (15), o a veces la complica con el caso de Sepola que hemos mencionado. El inventario que aquí hemos trabajado es un rosario de casos de ambos tipos como podrá observar el lector. Hay que precisar que nuestro interés fue identificar obras conservadas en repositorios contemporáneos a través de los catálogos electrónicos ya citados, para poder determinar de forma más precisa el número de ediciones que

28 Instrumentos disponibles en las páginas http://www.mcu.es/bibliotecas/MC/CCPB/index.html; http://www.sbn.it/opacsbn/opac/iccu/free.jsp; y http://retro.hebis.de/ 
ya no se localizan por cualquier razón, entre ellas la destrucción intencionada o no de la misma. Sólo cuando esta condición no se cumple acudimos a repertorios bibliográficos y cuando se trató de ediciones mexicanas a catálogos de instituciones de nuestro país. ${ }^{29}$ La localización casi puntual de impresos novohispanos en las instituciones mexicanas ayuda a confirmar la idea de que se trató de una producción orientada básicamente al mercado interior.

Hay que precisar que nos interesa localizar ediciones conservadas, porque este inventario forma parte de un conjunto de documentos recuperados en la investigación que estamos desarrollando y que hemos citado. En este sentido, es significativo anotar que no hemos podido localizar el $5 \%$ de las ediciones que Arangoiti poseyó, que son un total de 21 registros. En la mayoría de estos casos, no se ha logrado identificar la edición que fue registrada y, en otros, porque no se ha conseguido identificar al autor. En aquellos casos en los que no se registró la fecha y lugar de una obra, o en los que la obra no coincide con el año de edición preferimos anotar la que se reconoce como la primera de la ciudad inscrita. Asunto que como hemos mencionado es la forma común de trabajo cuando se trata de inventarios que no contienen muchos datos para la identificación de las obras registradas. Así, sólo después de este engorroso pero fascinante proceso, la información que se ha recuperado podrá ser analizada según el interés o matiz que se quiera distinguir.

Es este el caso del documento que trabajamos puesto que permite, por un lado, un análisis general de los datos contenidos en el inventario y, por otro, la identificación de ejemplares de las obras registradas. Dicha forma se ha probado ya con buenos resultados en otros trabajos porque permite presentar (Barrio 2000, 142-143) una visión general de la colección bibliográfica y, al paralelo, nos permite presentar una versión paleográfica del documento. Peculiaridad que es poco común y que los interesados en estos temas solemos agradecer. Lamentablemente en este caso, sólo podemos presentar la transcripción del inventario pero no de las ediciones localizadas, ya que de forma completa es complicado de publicar en esta revista.

Es por ello que, siguiendo a Bas (1998), podemos decir que es un documento al que lo distinguen sus particularidades porque permite analizar una cantidad importante de datos. Entre ellos el tipo de material, el formato, los años, lugares, la lengua, temática y el precio del avalúo. Este último punto en particular no suele ser un asunto al que se le haya dado una cierta relevancia. Pero es un dato que resulta fundamental porque la comparación de tal información en instrumentos semejantes nos permitirá analizar asuntos relacionados

29 Lamentablemente nuestra experiencia de investigación ha mostrado que no siempre los registros bibliográficos coinciden con las obras físicas, de ahí la diferenciación. 
con el aumento o disminución de los precios en la venta y compra de los libros en el pasado (Dadson 1987, 33). Para poder explicar el tipo de biblioteca presentamos la transcripción del documento original y añadimos sólo los autores identificados; en algunos casos puntuales información sobre una edición concreta en nota a pie. ${ }^{30}$ Se ha respetado la forma gramatical y ortográfica de la época, resaltando en cursiva los datos originales del documento. La única adición de este dato y que va entre corchetes es el precio de los libros, que se incluye en la memoria en la forma que se acostumbraba, es decir, en una columna a la derecha del documento, indicando según la posición si se trataba de pesos y de reales (v. gr. Đoo2p2: dos pesos y dos reales).

\section{Memoria de los libros de Domingo de Arangoiti}

\section{Libros en folio}

5. Marco Antonio Sabeldi. Suma de diversos tratados. falto el tomo 60 en Colonia 1707 [9 pesos].

[1] Sabellius, Marco Antonio

5. Primer sobre el Derecho Canonico. impresion Augustas en 1709 [7 pesos]

[2] Krimer, Ferdinand (S.I.)

3. Caprisolato. Decisiones en Ginebra 1706 [5 pesos]

[3] Capecelatro, Ettore

1. Julio Claro en Leon 1572 [2 pesos]

[4] Claro, Julio (1525-1575)

1. Paulo Ymelo de Catedrales Cremone en Leon 1670 [1 peso 4 reales]

[5] Melio, Giovanni Paolo

1. Valasco. Alegaciones en Portugal 1622 [1 peso 2 reales]

[6] Vallasco, Thomae

1. Solis. Conquista de Mexico. Barcelona 1691 [1 peso 4 reales]

[7] Solís, Antonio

30 La versión completa de esta memoria se integrará con las otras en el producto final de la investigación que hemos mencionado. 
1. Ayoza de partitionibus Madrid 1584 [1 peso 6 reales]

[8] Ayerbe de Ayora, Antonio ${ }^{31}$

1. Antonio Lains. Varias interpretaciones en Zaragoza 1720 [1 peso]

[9] Lanz y Lozano, Miguel Antonio

1. Conriado de Contratos Venecia 1580 [1 peso]

[10] Summenhart, Conrad (1465-1520)

1. Bocabulario de Antonio de Nebrija en Madrid 1758 [2 pesos 2 reales]

[11] Antonio de Nebrija (1444-1522)

1. Ordenanzas del Consejo Real de las Indias en Madrid 1747 [4 reales]

[12] Consejo de Indias.

4. Aristocracia Eclesiastica en Venecia 1703 (4 pesos)

[13] No se ha identificado

3. Paz Jorian en Colonia 1729 [6 pesos]

[14] Pacis Jordani, Vicentinis

12. Blas Altimaro. Sus obras en Napoles 1700 [14 pesos]

[15] Aldimari, Biagio (1641-1713)

4. Jonduto. sus obras en Leon 1659 [6 pesos]

[16] Tonduti, Pierre François de ${ }^{32}$

2. Arnoldo de Reiger en Colonia 1704 Corregido [3 pesos]

[17] Reyger, Arnold von

1. Philipus Bonani. Numismata Sumorum Pontificum en Roma 1696. con Laminas [4 pesos]

[18] Bonanni, Philippo (S.I.)

31 Hemos localizado la edición siguiente: Tractatus de partitionibus bonorum communium inter maritum et uxorem \& filios ac baeredes eorum... En Granada: por Rene Rabut y Nicolas Morpin, 1586 (ССРB000152247-7), por lo que la registrada en esta memoria podría ser la edición más antigua de la que se tenga noticia.

32 En este caso hemos localizado dos ediciones posibles: Tractatus de praeventione Iudiciali seu De Contentione iurisdictionum...Lugduni: sumpt. Phil. Borde, Laur. Arnaud \& Cl. Rigaud, 1659 (ССРB000040569-8) y Quaestionum et resolutionum legalium libri duo... (Lugduni: sumpt. Phil. Borde, Laur. Arnaud \& Claud. Rigaud, 1659 (CCPB000136983-0) 
1. Oros de Apicibus juris Leon 1733 [1 peso 2 reales]

[19] Oroz, Jerónimo de

1. Ybone sobre el Digesto en Paris 1659 [2 pesos]

[20] Yuone, P. (O.F.M. cap.)

1. Balmaceda de Colectis en Leon 1692 [1 peso 4 reales]

[21] Balmaseda de la Puente y Sobremonte, Diego

5. Donato de Marinis sus obras Leon 1675 [9 pesos]

[22] Marinis, Donato Antonio de 33

4. Padre Luis de Molina de justitia et jure. en Colonia 1614 [3 pesos]

[23] Luis de (S.I.) $(1535-1600)^{34}$

2. Rosental de Feudis en Colonia 1610 [1 peso 4 reales]

[24] Rosenthall, Heinrich von

2. Antunez de Portugal de Donatione Leon 1699 [2 pesos]

[25] Antunez, Dominicus

5. Mendo. sus obras en Leon 1668 [9 pesos]

[26] Mendo, Andrés (S.I.) (1608-1684) ${ }^{35}$

\section{Pareja de Varios Ynstrumentos en Madrid 1643 [2 pesos 4 reales] [27] Pareja y Quesada, Gabriel}

33 También en este caso hay dos ediciones posibles: Iuris allegationes insignium iurisconsultorum urbis Regiae Neapolis collectae a D. Donato Antonio De Marinis...; cum gemino indice... rerum \& verborum notabilium. Lugduni: sumpt. Laurentii Arnaud, Petri Borde, Ioan. \& Petri Arnaud, 1675 (ССB000045781-7); y D. Donati Antonii De Marinis... Resolutionum Iuris liber primus. Lugduni: scumpt. Laurentii Arnaud, Petri Borde, Ioan. \& Petri Arnaud, 1675 (CCPB000210270-6).

34 Son seis tomos de la edición.

35 Existen tres ediciones que se corresponden con los datos: R. P. Andreae Mendo Meronensis, $e$ Soc. Iesu... Bullae S. Cruciate elucidatio, vbi bulla communis viuorum, lacticiniorum pro ecclesiasticis, compositionis $\mathcal{E}$ defunctorum, necnon facultates commissarii generalis cruciate exponuntur... cum duplici indice, altero disputationum et capitum, altero rerum... Lugduni: sumptibus Horatii Boissat, \& Georgii Remeus, 1668 (CCPB000041387-9); R. P. Andreae Mendo... Soc. Iesu... De ordinibus militaribus: disquisitiones canonicae, theologicae, morales et bistoricae pro foro interno \& externo: opus elaboratum ad praxim ipsorum ordinum nec-non Iurisprudentum \& confessariorum... Lugduni: sumptibus Horatii Boissat, \& Georgii Remeus, 1668 (CCPB000050757-1); R.P. Andreae Mendo... e Soc. Iesu... De iure academico: selectae quaestiones theologicae, morales, iuridicae, historicae \& politicae, de academiis, magistratibus, collegiis, professoribus, candidatis \& Scholasticis... Lugduni: sumptibus Horatii Boissat, \& Georgii Remeus, 1668 (CCPB000055197-X). 
10. Viana Coordinado en Leon 1680 [11 pesos]

[28] Diana, Antonino (CC.RR.MM.) (1585-1663)

1. La Suma del dicho [1 peso]

[29] Diana, Antonino (CC.RR.MM.) (1585-1663)

3. Alexandro Tartagani. Concilios. Leon 1535 [3 pesos]

[30] Tartagni de Imola, Alessandro (1424-1477)

5. Andrés Tiraquelo. trunco. en Leon 1584 [3 pesos 4 reales]

[31] Tiraqueau, André (1488-1558) 36

1. Alexander ab Alexandro. Addiciones Atiraquelo en Leon 1554 [1 peso 6 reales]

[32] Tiraqueau, André (1488-1558)

2. Garzia de Beneficijs en Colonia 1758 [3 pesos]

[33] García, Nicolás

10. Castillo Sotomayor en Colonia 1726 [16 pesos]

[34] Castillo Sotomayor, Juan del (1563-1640)

1. Melo. Adiciones a Castillo [2 pesos]

[35] Melius, Ioannes Paulus ${ }^{37}$

4. Nigro Ciriaco. Controversias. Leon 1672 [4 pesos]

[36] Negri Ciriaco, Francesco (m. 1637)

2. Amaya sobre el Codigo en Leon 1639 [2 pesos 4 reales]

[37] Amaya, Francisco de

2. Valenzuela. Concilios en Leon 1671 [4 pesos 4 reales]

[38]Valenzuela Velázquez, Juan Bautista (1574-1645)

36 De este autor y en esa fecha también hay varias opciones: Andreae Tiraquelli... De vtroque retractu municipali et conuentionali commentarii duo... Quarta hac eademque postrema editione... Lugduni: apud Gulielmum Rouillium ..., 1584 (CCPB000026174-2); Tractatus varii... Lugduni: Guilielmus Rovillius, 1584 (CCPB000026191-2); Andreae Tiraquelli... Commentari de nobilitate et iure primigeniorum. Lugduni: apud Guilielmum Rouillum sub scuto Veneto, 1584 (IT \ICCU \SIPE \008658).

37 Se trata del tomo 10 de la edición D. Joannis Del Castillo Sotomayor... Quotidianarum controversiarum juris tomus primus [-octavus]... Coloniae Allobrogum: sumptibus Perachon \& Cramer, 1726-1727 (IT \ICCU $\backslash R M G E \backslash 001076)$. 
2. Decisiones de varios Autores en Leon 1618 [2 pesos 4 reales]

[39] Iglesia Católica. Rota Romana

1. Amato. varias resoluciones Leon 1658 [2 pesos]

[40] Amato, Antonino (m. 1653)

1. Robito. Concilios sin Caratula [2 pesos]

[41] No se ha identificado

3. Gaspar Mansio. Biblioteca aurea en Franco fuerte 1695 (6 pesos) [42] Manzus, Caspar

3. Antonio Gomez con su Ayllon en Leon 1674 (4 pesos 4 reales) [43] Gómez, Antonio ${ }^{38}$

1. Vrrisi enciclopedia juris Colonia 1679 [1 peso]

[44] No se ha identificado.

2. Crespo de Valdaura observaciones en Leon 1662 [3 pesos]

[45] Crespi de Valldaura, Cristóbal (1599-1671)

2. Jacobo Conserrio. Varias resoluciones en Leon 1683 [3 pesos] [46] Cáncer, Jaime (1520-1592)

2. Juan Bautista Ciarlini. Controversias en Leon 1670 [2 pesos 4 reales] [47] Ciarlini, Giovanni Battista

4. Joseph Mascardo de Aprobaciones Franfort 1727 [12 pesos] [48] Mascardi, Giuseppe (1588)

4. Juan Bautista Larrea. Alegaciones y Decisiones en Leon 1679 [5 pesos] [49] Larrea, Juan Bautista de (1645)

38 Para este autor también existen varias posibilidades: D. Antonii Gomesii... Ad leges Tauri commentarium absolutissimum. Lugduni: ex typographiâ Michaelis Goy, 1674 (CCPB000054756-5); D. Antonii Gomesij... Variarum resolutionum iuris civilis communis et regii commentaria: tomis tribus distincta... annotationes Emanueliis Soarez a Ribeira... Lugduni: ex typographiá Michaelis Goy, 1674 (CCPB000054757-3); y D. D. Ioannis de Ayllon Laynez I. C... Illustrationes sive Additiones eruditissimae ad varias resolutiones Antonii Gomezii: quibus non solum ipsius Gomezij doctrina novum ... accipit, verumetiam ... de testamentis contractibus $\mathcal{E}$ delictis quaestiones ... enodantur E elucidantur... Lugduni: sumptibus fratrum Anissoniorum \& Ioannis Posuel, 1676 (CCPB000044833-8). 
2. Padre Alexandro Ludovici. Decitiones de la Rota. en Roma 1622 [2 pesos] [50] Iglesia Católica. Rota Romana

6. Diccionario de la Lengua Castellana. en Madrid 1739 [45 pesos]

[51] Real Academia Española

4. Fontanela. de Pactis Genova 1685 [5 pesos]

[52] Fontanella, Juan Pedro (1576-1680) ${ }^{39}$

5. Salgado sus obras en Leon 1672 [10 pesos]

[53] Salgado de Somoza, Francisco

8. Otro dicho de Diana sin coordinar. Madrid 1625 [5 pesos]

[54] Diana, Antonino

4. Recopilacion de Leyes de Yndias. Madrid 1756 [12 pesos]

[55] Carlos II, Rey de España (1661-1700)

2. Murillo. Curso Canonico Madrid 1773 [6 pesos]

[56] Murillo Velarde, Pedro (S.I.)

1. Valeron. de Transationibus Leon 1665 [1 peso 4 reales]

[57] Valeron, Manuel Román (S. XVII)

4. Juan Bautista Acosta sus obras. Venecia 1610 [4 pesos]

[58] Costa, Johannes Baptista ${ }^{40}$

4. Solorzano. falto de las obras postumas en Madrid 1629 [9 pesos]

[59] Solorzano Pereira, Juan (1575-1654)

4. Postius de Gulastatione. Genova 1717 [4 pesos]

[60] Postius, Ludovicus

4. Donelo. sobre el derecho Civil. Francfort. 1622 [4 pesos]

[61] Doneau, Hugues

39 Edición en dos volúmenes.

40 Existen dos opciones para este registro: De Iudiciis theorico praxis hoc est Tractatus compendiosus... Venetiis: apud Iacobum Antonium Somaschum, 1610 (ССРB000442087-X); y Tractatus Io. Baptistae Costae... De portione rata. Venetiis: apud Societatem Minimam, 1610 (CCPB000731455-8). 
6. Gonzalez Tellez. sobre las Decretales Leon 1715 [12 pesos]

[62] González Téllez, Manuel

1. Salazar. Coleccion del Govierno general Madrid 1764 [8 pesos]

[63] Martínez Salazar, Antonio

1. Gonzalez. à Regula Chancelaria Leon 1676 [1 peso 4 reales]

[64] González, Jerónimo

4. Reinfestuel sobre el derecho Canonico Venecia 1773 [10 pesos]

[65] Reiffenstuel, Anaklet (O.F.M.) (1642?-1703)

4. Enrico Pering. sobre el Derecho Canonico. en Lisboa 1722 [9 pesos] [66] Pirhing, Ehrenreich (S.I.)

5. Badespen sobre el derecho Canonico. Venecia 1769 [16 pesos]

[67] Espen, Zeger-Bernard van

4. Corteada. Decisiones en Leon 1699 [5 pesos]

[68] Cortiada, Miguel de (m. 1691)

1. Alfonzo de Lara. en Madrid 1768 [3 pesos 4 reales]

[69] Pérez de Lara, Alfonso ${ }^{41}$

1. Antonio Cordova de Lara de anosendis. España 1757 [6 reales]

[70] Córdoba de Lara, Antonio (m. 1586)

3. Concilio Mexicano, Concilios Provinciales y Conquista de Mexico por el señor Lorenzana. Mexico 1769 [9 pesos]

[71] México (Archidiócesis). Concilio provincial (1². 1555. México)

3. Concilio tridentino: con obras de Galemar. Madrid 1762 [3 pesos 4 reales] [72] Concilio de Trento (1545-1563)

41 En este caso también hay dos opciones: Compendio de las tres gracias de la Santa Cruzada, subsidio y escusado que su Santidad concede a... Phelipe III... para gastos de guerra contra infieles... recopilado de mandado del señor... Martin de Cordova... por el licenciado Alonso Perez de Lara... En Madrid: en la imprenta de Antonio Perez de Soto, 1768 (CCPB000142158-1); e Ildephonsi Perez de Lara toletani... Compendium vitae hominis in iure fori et poli usque ad perfectam aetatem et senectam: tractatus perutilis continens frequentiosa, quae tam in judiciis... Matriti: in officina D. Antonii Mayoral: sumptibus regalis Societ. Typograph. \& Bibliop., 1768 (CCPB000173903-4). 
9. Abad Panormitan. Venecia 1582 [9 pesos]

[73] Niccolò de Tudeschi, Arzobispo $(1386-1445)^{42}$

2. Gasendo Philosophia Epicurea Leon 1675 [3 pesos]

[74] Gassendi, Pierre (1592-1655) ${ }^{43}$

1. Rosa Consultationes en Leon 1678 [2 pesos]

[75] Rosa, Giuseppe di

6. Castro Palas. opera moral en Leon 1700 [7 pesos]

[76] Castropalao, Hernando de (S.I.) (1583-1633)

3. Francisco Pereyra. Controversias. Del derecho jure enfiteusis en Liri 1585

[4 pesos]

[77] Caldas Pereira y Castro, Francisco de (1543-1597)

1. Patronato del señor Rivadeneira. Madrid 1755 [1 peso 4 reales]

[78] Ribadeneyra y Barrientos, Antonio Joaquín

6. Thesauro indico del Padre Luis de Avendaño en Antuerpia 1688 [20 pesos]

[79] Avendaño, Diego de (S.I.)

2. Julio Claro. sus obras en Genova 1739 [4 pesos 4 reales]

[80] Claro, Giulio (1525-1575)

2. Alvaro Velasco. sus obras en Colonia 1735 [5 pesos]

[81] Vaz, Alvaro (1526-1593)

2. Ramos del Manzano de Leyes Julianas en Madrid 1668 [7 pesos]

[82] Ramos del Manzano, Francisco

42 En este caso también hay dos opciones: Abbatis panormitani Commentaria primae partis in primum decretalium librum... Venetiis: apud Iuntas, 1582 (CCPB000226534-6); Abbatis Panormitani Consilia iurisq. Responsa, ac quaestiones, omnibus cum iudicantibus, tum consulentibus apprimè conducentia: bac postera vero editione recognita, atque ab innumeris erroribus, quibus ob temporis vetustatem, [et] librariorum recentem iniuriam vbiq[ue] deprauata, mutila passim, [et] plerisque in locis decurtata vsque adeo deprebendebantur, vt nullus plane sensus esset, tam in textu, quàm in allegationibus, summo studio vindicata, [et] integritati suae restituta... Venetiis: apud Iuntas, 1582 (CCPB000855274-6).

43 Tít. en portadilla: "Epicuri philosophiae / per Petrum Gassendum...". Información tomada del catálogo. 
8. Julio Caponi sus obras. Venecia 1709 [14 pesos]

[83] Capone, Giulio (1612-1673) ${ }^{44}$

2. Meres de Maioratibus en Leon 1678 [4 pesos]

[84] Pelaéz de Mieres, Melchor

2. Fraso de Regio. Patronato. Madrid 1677 [5 pesos]

[85] Frasso, Pedro

2. Menoquio de Presuntionibus. Leon 1564 [3 pesos]

[86] Menochio, Giacomo

4. Las 7 partidas del Señor Gregorio López Valladolid 1577 [12 pesos]

[87] López de Tovar, Gregorio

1. Escobar de Pulitate, et novilitate en Leon 1678 [2 pesos 2 reales]

[88] Escobar del Corro, Juan

1. Muñoz de Escobar de ratiocinijs en Leon 1733 [2 pesos 4 reales]

[89] Muñoz de Escobar, Francisco

1. Juan de Escobar y Corro. de Solicitantibus en Confetione en Leon 1737 [1 peso 6 reales]

[90] Escobar de Corro, Juan

1. Del derecho de vtriusque foro en Leon 1575 [6 reales]

[91] No se ha identificado

2. Vela Disertationes juris en Leon 1575 [4 pesos]

[92] Vela de Oreña, José

44 Identificamos una edición anterior: Disceptationum forensium ecclesiasticarum, civilium, et moralium pluribus in Casibus decisarum, tomus primus (-quintus)... Venetiis: apud Paulum Balleonum, 1705 (IT \ICCU $\backslash F O G E \backslash 012813$ ), que también se encuentra en la biblioteca de otro Oidor. (Fernández 1999-2000, 109). 
4. Covarrubias con aditiones de Farias Genova 1762 [12 pesos]

[93] Covarrubias y Leiva, Diego ${ }^{45}$

2. Politica de Bobadilla. Medina del Campo 1608 [4 pesos 4 reales]

[94] Castillo de Bovadilla, Jerónimo (n. 1547)

3. Segismundo Escasea. sus obras. en Colonia 1670 [4 pesos]

[95] Scaccia, Segismundo

1. Constituciones de la Universidad de Mexico en dicho 1775 [1 peso 4 reales] [96] Universidad de México

3. Fragoso de Regimine Reipublice. Leon 1667 [5 pesos]

[97] Fragoso, Baptista (S.I.) (1559-1639)

19. Agustin Barbosa. sus obras. en Leon 1716 [30 pesos]

[98] Barbosa, Agostinho (1590-1649)

2. Castejon. Alfabeto Juridico. Madrid 1678 [4 pesos]

[99] Castejón, Gil de

1. Lesio de Justitiu, et jure Leon 1630 [2 pesos]

[100] Lessius, Leonardus (1554?-1623)

4. Alfonzo de Azevedo. sobre la recopilacion. Madrid 1612 [18 pesos]

[101] Acevedo, Alfonso de

1. Magro. Indice de la recopilación. Alcala 1726 [3 pesos]

[102] Magro y Zurita, Santiago

1. Escalona. Gazofilacio Regium Perubicum en Madrid 1675 [2 pesos 4 reales] [103] Escalona y Agüero, Gaspar de

45 En este caso también hemos encontrado dos opciones: Didaci Covarruvias a Leiva, toletani episcopi segobiensis... Opera omnia, jam post varias editiones correctiora..., cum Auctoris Tractatu in tit. De frigidis E maleficiatis..., accesserunt de novo Joannis Uffelliij. c. patricii Bruxellensis, in Variarum Resolutionum libros; notae uberiores cum duplici indice, capitum E rerum locupletissimo, suis numeris restituto. Tomus primus [-secundus]. Genevae: sumptibus fratrum de Tournes, 1762 (IT \ICCU $\backslash B A S E \backslash 002860$ ); y de Ibáñez de Faria, Diego. D. Didaci Ybañez de Faria... additiones, observationes et notae ad libros variarum resolutionum... Didaci Covarrubias a Leiva... Genevae: sumptibus Fratrum de Tournes, 1762 (CCPB000059448-2). 
1. Beitia. Norte de la contratacion de las Yndias. en Sevilla $1672[1$ peso 4 reales]

[104] Veitia Linage, José de

1. Paz. Praxis ecclesiastica et Secularis. Madrid 1770 [3 pesos 4 reales] [105] Suarez de Paz, Gundisalvo

1. Curia Philipica. en Madrid 1771 [5 pesos]

[106] Hevia Bolaños, Juan de

1. Alfaro de Ofitio Fiscalis. Madrid 1639 [1 peso 4 reales]

[107] Alfaro, Francisco de

1. Andres Georgi. Alegationes. en Napoles 1555 [1 peso]

[108] De Giorgio, Giovanni Andrea

1. Politica de Villadiego en Madrid 1747 [2 pesos]

[109] Villadiego Vascuñana y Montoya, Alonso de

3. Comentarios de la recopilacion de Yndias [4 pesos]

[110] Carrasco del Saz, Francisco $1620^{46}$

1. Pedro Nogerol. Alegaciones juros. Leon 1683 [2 pesos]

[111] Díez de Ribadeneyra Noguerol, Pedro (m. 1640) ${ }^{47}$

1. Bartolome Bersani de Privilegijs et juribus en Leon 1799 [1 peso 2 reales] [112] Bersani, Bartolomeo (1668-1707) ${ }^{48}$

3. Montalva de jure superbenente. Lisboa 1760 [4 pesos]

[113] Hontalba y Arce, Pedro

1. Gaelota responsa fiscalia. Colonia 1686 [2 pesos 4 reales]

[114] Capece Galeota, Fabio

1. Otero. de ofizialibus Reipublice Colonia 1732 [2 pesos 4 reales]

[115] Fernández de Otero, Antonio

46 Es posible que se trate de esta obra, pues su autor fue el glosador de la Nueva Recopilación, además de asesor de virreyes y oidor de la Audiencia de Panamá.

47 En este caso debemos registrar la edición más antigua impresa en 1676.

48 Sólo hemos localizado una edición de cien años antes, en 1699. 
1. Gamboa. ordenanzas de Minas. Madrid 1761 [7 pesos]

[116] Gamboa, Francisco Xavier de

1. Roxas Almanza. de Inconpatibilitate. Duplicado en Colonia 1738 [5 pesos]

[117] Rojas Jordan de Tortosa, Hermenegildo de

1. Matheo. de re Criminali. Leon 1702 [2 pesos 4 reales]

[118] Mateu y Sanz, Lorenzo (1618-1680)

2. Villarroel. La union de los dos cuchillos en Madrid 1656 [4 pesos 4 reales]

[119] Villarroel, Gaspar de (O.S.A.) (ca. 1587-1665)

1. Alfonso de Olea. Deciciones en Leon 1720 [2 pesos 4 reales]

[120] Olea, Alfonso de

2. Puga, y Feijoò. sus obras en Leon 1735 [2 pesos 4 reales]

[121] Puga y Feijoo, Juan

4. Guerra. Epitome del Bulario. Venecia 1772 [14 pesos]

[122] Guerra, Luis

3. Recopilacion de Castilla. Madrid 1775 [20 pesos]

[123] Asso y del Río, Ignacio de (1742-1814)

4. Biblioteca de Ferraris. en Barsani 1772 [18 pesos]

[124] Ferraris, Lucio (O.F.M.) ${ }^{49}$

3. Mariana. Historia de España. Madrid 1741 [9 pesos]

[125] Mariana, Juan de (S.I.)

2. Juan Bautista Ciarlini. Controversias Leon 1671 [3 pesos]

[126] Ciarlini, Giambattista

5. Arnoldo, de justitia et jure. Ynglostad 1671 [7 pesos]

[127] Haunold, Christophe (S.I.)

1. Egidio Bosij. tratados varios. Basilea 1624 [1 peso 6 reales] [128] Bossi, Egidio 
1. De Pandectas Canonicas. falto. Paris 1587 [2 pesos]

[129] Bude, Guillaume

2. Pandectas Civilis. con notas de Gotofredo en Colonia 1756 [14 pesos]

[130] Brunnemann, Johann (1608-1672)

3. Dominguez. Ylustracion de la Curia. Valencia 1770 [5 pesos 4 reales]

[131] Domínguez Vicente, José Manuel

1. Carrasco. sobre la recopilacion. Madrid 1648 [2 pesos 4 reales]

[132] Carrasco del Saz, Francisco ${ }^{50}$

1. Espino de Testamentos. Sevilla 1676 [1 peso 2 reales]

[133] Espino de Cáceres, Diego ${ }^{51}$

5. Salzedo Gonzalez. sus obras. Madrid 1729 [10 pesos]

[134] Gonzalez de Salcedo, Pedro

1. Padre Geronimo Sabredo. Francfort 1555 [1 peso 2 reales]

[135] No se ha identificado

1. Mostaro de Causas pias. Venecia 1735 [3 pesos 4 reales]

[136] Mostazo, Francisco ${ }^{52}$

1. Aviles. In capite pretorio. Madrid 1597 [2 pesos]

[137] Avilés, Francisco de

1. Gaspar Beitia. de dezima Tutori. Madrid 1592 [1 peso 4 reales]

[138] Baeza, Gaspar ${ }^{53}$

2. Rodrigo Suarez. con su adicionador Baldesi en Salamanca. 1557 [1 peso] [139] Suárez, Rodrigo ${ }^{54}$

50 Localizamos la edición de 1620. La antep. de obras completas tiene pie de imprenta propio: "Cum privilegio Madriti, per Iulianum de Paredes, Anno MDCXLVIII". Datos extraídos del catálogo. En ese año de 1648 se publicó en Madrid la obra del autor Opera omnibus iurium scientiae.

51 Registramos aquí la edición más antigua de 1587.

52 Obra con varias ediciones impresas en el XVII y XVIII.

53 Contiene: De non meliorandis ratione dotis filiabus; De inope debitore creditori addicendo; De decima tutori hispanico iure praestanda. Datos extraídos del catálogo.

54 Localizamos la edición de 1568 y las adiciones en 1590. 
1. Feliziano de Sensibus. Madrid 1605 [1 peso 2 reales]

[140] Solís, Feliciano de

1. Gaspar Bactian. ad Leges limitationes. Granada [4 reales]

[141] Baeza, Gaspar

1. Bernardino Tototi. de Causa servitutis Venecia 1705 [6 reales]

[142] Tollotti, Bernardino

13. Juan Gutierrez sus obras. Salamanca 1537 [14 pesos]

[143] Gutiérrez, Juan (ca. 1535-1618)

1. Casani. Catalugus gloris mundi. Colonia 1652 [1 peso 6 reales]

[144] Chasseneux, Barthélémy de (1480-ca. 1541)

1. Perecio. Catena Selecta. Madrid 1643 [1 peso]

[145] Perez, Antolín (C.S.B.)

2. Diaz de Mena. Questiones Criminales en Medina del Campo 1603 [2 pesos]

[146] Flórez Díez de Mena, Blas

2. Pedro Rebufo. Placis beneficiario. Leon 1564 [1 peso 6 reales]

[147] Rebuffi, Pierre

2. Geronimo Roca. Disputationes juris. Colonia 1697 [2 pesos 2 reales]

[148] Rocca, Hieronymus

1. Pinelo. Selecta juris trunco Venecia 1613 [4 reales]

[149] Pinelo, Benito

1. Olano. Concordia juris Antuerpia 1757 [4 reales]

[150] Martínez de Olano, Juan

1. Juan Parladorio. trunco. Salamanca 1595 [4 reales]

[151] Yáñez Parladorio, Juan

2. Juan Bautista hodiermas decitiones Ginebra 1672 [2 pesos 4 reales]

[152] Odierna, Giovanni Battista (ca. 1602-1678) 
1. Paz de Fenuta en Leon 1671 [1 peso]

[153] Paz, Cristobal de

1. Vizente Filuri de statu Clericorum. Madrid 1626 [1 peso]

[154] Filliucci, Vicenzo (S.I.)

2. Francisco Torrellanca. Jus espirituales, et epitome delictorum. Cordova 1635 [2 pesos 2 reales]

[155] Torreblanca Villalpando, Francisco

1. Resolutiones forenses Petri Antolini Ginebra 1686 [1 peso 6 reales] [156] Attolini, Giovanni Pietro

1. Francisco Balduini. Institutiones juris Civilis. Leon 1583 [1 peso] [157] Balduin, François

1. Mariscoti varias resoluciones en Francfort 1617 [1 peso]

[158] Mariscotti, Ercole (1621)

1. Jacobo Simanca. de Catolica institutione en Madrid 1569 [1 peso 2 reales] [159] Simancas, Jacobo de

1. Juan Bautista Samanieti. Controversias forenses en Ginebra 1688 [1 peso 2 reales]

[160] De Luca, Giovanni Battista (1614-1683)

1. Lelij Altigradi. Concilios. en Luca 1643 [2 pesos]

[161] Altogradi, Lelio ${ }^{55}$

3. Joseph Vrsirlo. Consultationes forenses. en Colonia 1733 [3 pesos]

[162] Orceoli, Giuseppe

3. Lazerda. sobre Virgilio Leon 1612 [4 pesos]

[163] Cerda, Juan Luis de la (S.I.)

1. Virgilio, con notas de varios Autores. Basilea [1 peso 4 reales]

[164] Virgilio Marón, Publio 
2. Sebastian Guasino. opera criminalis Francfort 1714 [2 pesos]

[165] Guazzini, Sebastiano

1. Montalvo. fuero real de España. Salamanca 1569 [1 peso]

[166] Díaz de Montalvo, Alfonso (1405-1499)

1. Otro dicho en letra gotica [6 reales]

[167] Son datos generales que no permiten una identificación.

2. Camili Capisci. Praxis judiciaria. Roma. 1680 [1 peso 6 reales]

[168] Cappucci, Camillo

3. Mathei Burati. Decitiones de la Rota. Leon 1661 [3 pesos 4 reales]

[169] Buratti, Mateo

2. Agustin Tornelio. Annales Sacre Antuerpia 1616 [2 pesos]

[170] Tornielli, Agostino (1543-1622) ${ }^{56}$

2. Rolandi del Valle. Concilios. Leon. 1573 [2 pesos]

[171] Della Valle, Rolando

1. Padre Francisco Suarez. de Legibus Antuerpia 1613 [1 peso 4 reales]

[172] Suárez, Francisco (S.I.) $(1548-1617)^{57}$

1. Curso Salmantino moral. trunco. en Madrid 1723 [1 peso 2 reales]

[173] Collegii Salmanticensis FF. Discalceatorum B. Mariae de Monte Carmeli ${ }^{58}$

2. Serafini. Decitiones. Colonia 1615 [2 pesos]

[174] Olivier, Serafín

3. Palavicini. Poliantea Canonica. Colonia 1728 [4 pesos 4 reales]

[175] Paravicino, Joannes Paulus

56 Hemos localizado una edición en Fráncfort de 1616 (CCPB000123610-5). La edición localizada de Antuerpiae es impresa por Morentus en 1620.

57 Obra también impresa en Lugduni: sumptibus Horatij Cardon, 1613.

58 El autor del tomo primero es Francisco de Jesús María, del tomo segundo, tercero y cuarto es Andrés de la Madre de Dios y del quinto Sebastián de San Joaquín. Nota del catálogo colectivo. 
5. Pedro Barbosa. Sus obras enbijadas de diferentes impresiones [4 pesos $]^{59}$ [176] Este autor fue muy reputado en su tiempo, por lo que se publicaron muchas obras en Madrid, Zaragoza, Lisboa, Lyon, Venecia, Fráncfort, Ginebra, Tournon y otras.

2. Francisco Peña. Deciciones en Leon 1648 [2 pesos 2 reales]

[177] Peña, Francisco (1540-1612)

1. Roxas decisiones de la Rota. Leon 1662 [1 peso 2 reales].

[178] Rojas, Francisco de (O.F.M.)

2. Gabriel de Velasco. Index perfectus Leon 1662 [2 pesos]

[179] Álvarez de Velasco, Gabriel

1. Lezio de Justitita, et jure. Antuerpia 1617 [2 pesos]

[180] Lessi, Leonardo (S.I.) (1554-1623)

1. Pequera. Decitiones trunco en Barzelona 1605 [1 peso]

[181] Peguera, Luis de

1. Sarmiento. Selectas. Antuerpiea. trunco [1 peso]

[182] Sarmiento de Mendoza, Francisco ${ }^{60}$

2. Miguel de Caldero. Deciciones Criminales en Barzelona 1687 [3 pesos] [183] Calderón, Miguel de

1. Sinostrario. Formulario Criminal. Roma 1693 [1 peso]

[184] Sinistrari, Ludovico Maria (m. 1701)

1. Fernandez Miñaño. Vases Pontificis. Madrid 1674 [1 peso 2 reales]

[185] Fernández de Miñano, Francisco

1. Carranza. de parte humana. Madrid 1628 [1 peso 4 reales]

[186] Carranza, Alonso

59 Es posible que se trate de la palabra indígena "embijar" que significa pintar algo o a alguien con alguna sustancia vegetal, lo que podría indicarnos que se trataba de algún volumen decorado. Agradezco al Dr. Pedro Rueda su ayuda con este término.

60 En esta ciudad hay dos ediciones una impresa por Ioannem Keerbergium en 1616 y otra impresa por Hieronymum \& Ioannem Bapt. Verdussen, en 1661. 
1. Mexia de legione Pontificis Madrid 1607 [5 reales]

[187] Mejía y Ponce de León, Luis

1. Juan Rolin de Magestate Principis. en Valladolid 1568 [3 reales]

[188] Redin, Juan

1. Alvarado. de vltimas voluntades. sin caratula [2 reales]

[189] Rodríguez Alvarado, Diego ${ }^{61}$

1. Mexia. Tazacion del pan. Sevilla 1569 [1 peso 2 reales]

[190] Mejía Ponce de León, Luis

1. Casanate. de inmunitate gabele sin caratura [3 reales]

[191] Casanate, Luis de

1. Tello Fernandez. sobre las leyes de Toro Madrid 1595 [1 peso]

[192] Fernández Messia, Tello

1. Otalora. de nobilitute. Salamanca 1570 [6 reales]

[193] Arce de Otalora, Juan

1. Villaplana. de Brachio Militaris. Barzelona 1683 [3 reales]

[194] Vilaplana, Antoni de

1. Ripia de rentas reales. Barzelona 1694 [1 peso]

[195] Ripia, Juan de la

1. Marquecho de Bonorum divitione Madrid. 1601 [4 reales]

[196] Sanz Morquecho, Pedro

1. Guzman de divitionibus en Leon 1616 [1 peso]

[197] Guzmán Genzor, Alfonso de

1. Rodriguez de executione sententie Madrid 1613 [3 reales]

[198] Rodríguez, Amador

61 Consideramos que se trata de esta edición: De coniecturata mente defuncti ad methodum redigenda libri quatuor... Hispali: apud Ferdinandum Diaz..., 1578 (CCPB000025261-1). 
1. Cartebal de judicijs en Colonia 1729 [3 pesos]

[199] Carleval, Tomás

1. Antonio Mangili de subastationibus. Ginebra 1668 [6 reales] [200] Mangili, Giovanni Antonio

1. Brunont. Privilegios de regulares. Valencia. 1655 [6 reales] [201] Chassaing, Bruno (O.F.M.)

1. Cerbantes. sobre las Leyes de Toro. Mantua 1544 [6 reales] [202] Guillén de Cervantes, Juan

1. Pareja de diversis instrumentis Leon 1668 [3 pesos] [203] Pareja y Quesada, Gabriel (1601)

1. Abreu. sobre vacantes de Indias Madrid 1726 [6 reales] [204] Alvarez de Abreu, Antonio José

1. Famini. de resignatione Beneficiorum. en Colonia 1615 [1 peso] [205] Parisius, Flaminius (1563-1603)

1. Geronimo Marsili. vanitorium. Boemia 1523 [1 peso] [206] Marsili, Ippolito (1451-1529)

2. Pereira de Manu regia en Lisa 1622 [1 peso 4 reales] [207] Pereira de Castro, Gabriel (1571-1632)

1. Carabajal. Historia de Africa. trunco. granada 1757 [6 reales] [208] Marmol Carvajal, Luis del ${ }^{62}$

1. Fray Pedro de Aris. Historia de ala Ciudad de Abila. en Alcala 1607 [6 reales]

[209] Ariz, Luis (O.S.B.)

1. Fray Francisco de San Juan. Mision historial de Marruecos. en Sevilla 1708 [1 peso]

[210] Francisco de San Juan del Puerto (O.F.M.) 
1. Caramuel Philipus Prudens. Antuerpia. 1639 [1 peso]

[211] Caramuel Lobkowitz, Juan (O.Cist.) (1606-1682)

2. Berganza. Antiguedades de España. Madrid 1721 [3 pesos]

[212] Berganza, Francisco de (O.S.B.)

3. Fray Francisco de San Antonio. Cronica de la Provincia de San Antonio de Philipinas. Manila 1738 [3 pesos]

[213] Juan Francisco de San Antonio (O.F.M.)

1. Fray Gaspar de San Agustin. Conquista de las Yslas Philipinas. Madrid 1698 [1 peso]

[214] Gaspar de San Agustín (O.S.A.)

1. Espinosa. Cronica de los Misioneros. Mexico 1746 [1 peso]

[215] Espinosa, Isidro Felix de (1679-1755)

1. Salazar. Historia general de la Casa de Farnesio. en Madrid 1714 [1 peso 4 reales]

[216] Salazar y Castro, Luis de (1658-1734)

1. Eguiara. Biblioteca Mexicana. Mexico 1755 [1 peso]

[217] Eguiara y Eguren, Juan José de

2. Ribarola. Monarquia Española. Madrid 1736 [2 pesos]

[218] Rivarola y Pineda Rodríguez de Cárdenas, Juan Felix Francisco

1. Roxis. Historia Ymperial de Toledo. trunco en Madrid 1756 [6 reales] [219] Rojas, Pedro de, Conde de Mora

1. Ribarola. Nobleza de la Ciudad de Genova. Madrid 1729 [1 peso]

[220] Rivarola y Pineda Rodríguez de Cárdenas, Juan Félix Francisco

1. Lainez. El privado Cristiano. Madrid 1641 [6 reales]

[221] Lainez, José (O.S.A.)

1. Marquez. Origen de los Frayles de San Agustin en Salamanca 1718 [6 reales] [222] Márquez, Juan (O.S.A.) (1565-1621) 
1. Poritelo. Empresas Politicas, y Militares en Madrid 1731 [1 peso] [223] Pozuelo y Espinosa, Juan Antonio

1. Memorias de Phelipe de Comines. Amberes 1714 [3 pesos]

[224] Commynes, Philippe de (1445-1509)

1. Cienfuegos. Vida de San Francisco de Borja. Madrid 1717 [1 pesos 2 reales] [225] Cienfuegos, Álvaro (S.I.)

1. Fray Luis Pueyo. El hombre es la mejor, y peor criatura que ay. en Zaragoza 1704 [1 peso]

[226] Pueyo y Abadía, Luis, Arzobispo de Sta. María de Albarracín (O.C) (1640-1704)

1. Rodrigo Silva. Poblacion general de España en Madrid 1645 [1 peso 2 reales] [227] Méndez Silva, Rodrigo

1. Alfonzo de Olea. varios tratados. Genova 1723 [1 peso 4 reales] [228] Olea, Alfonso de

1. Castro de Potestate legis Salamanca 1550 [6 reales] [229] Castro, Alfonso de (O.F.M.)

1. Antonio de Castro. Alegaciones Canonicas en Madrid 1689 [1 peso] [230] Castro, Antonio de (Licenciado)

1. Joseph de Castro. Disertationes Canonicas en Madrid 1727 [1 peso] [231] Castro y Araujo, Jose

1. Antonio Gama. Decisiones. Madrid 1621 [1 peso]

[232] Gama, Antonio

1. Pablo Jamar. de rebus judicatorum. en Barzelona 1657 [6 reales] [233] Jammar, Juan Pablo

6. Pedro Gregorio. Sintomata juris. Leon 1532 [8 pesos]

[234] No se ha identificado

1. El Atlas moderno en [12 pesos]

[235] Sólo hemos encontrado con este título una edición de 1792 
13. Rodriguez. Fermosino. sus obras Colonia 1741 [25 pesos]

[236] Rodriguez Hermosino, Nicolás, Obispo de Astorga (1662-1669)

1. Establecimiento del orden de Santiago en Villafranca 1655 [3 reales]

[237] Orden de Santiago ${ }^{63}$

1. Barios publicados en tiempo del Señor Bucareli [2 pesos 4 reales]

[238] Podría tratarse de un volumen facticio que haya contenido publicaciones oficiales tales como instrucciones, bandos o reglamentos.

1. Montemayor autos acordados Mexico 1778 [5 pesos]

[239] Montemayor y Córdoba de Cuenca, Juan Francisco de ${ }^{64}$

1. Montealegre. Practica Civil y Criminal en Madrid 1614 [1 peso 4 reales] [240] Montealegre, Juan de

3. Farma de juris Patronato Roma 1718 [6 pesos 4 reales]

[241] Fargna, Francesco de ${ }^{65}$

1. Enao. Otia Salmantina. Salamanca 1707 [6 reales]

[242] Henao Colon y Larriategui, Bartolomé

1. Andres Baci de termis. Patabia 1711 [5 reales]

[243] Bacci, Andrea (1524-1600)

1. Olano. Concordia juris. Burgos 1715 [4 reales]

[244] Martínez de Olano, Juan ${ }^{66}$

1. Panormitano. Consultas civiles en Palermo 1631 [4 reales]

[245] Maia, Ippolito

1. Arias de Mesa varias resoluciones en Leon 1572 [1 peso 6 reales]

[246] Arias de Mesa, Fernando

63 La h. de grab. calc.: "Petrus de Villafranca sculptor regius fact Matriti 1662", retrato de Felipe IV. Datos tomados del catálogo.

64 Es un error evidente del escribano porque se trata de la única edición de la obra: Sumarios de las cedulas, ordenes y provisiones reales... Recopilacion de Leyes de las Indias... En Mexico: En la Imprenta de la viuda de Bernardo Calderon, 1678 (CCPB000645280-9).

65 Se trata de una edición en tres volúmenes, el dos y el tres fueron impresos en Roma por Giovanni Maria Salvioni. Al volumen dos le corresponde la fecha de 1718.

66 Sólo encontramos una edición de 1575, que es la misma que registra Palau (1990, T. V, 86). 
1. Pedro Noguerol de alegationibus en Leon 1693 [2 pesos 2 reales]

[247] Díez de Ribadeneyra Noguerol, Pedro (m. 1640)

1. Arnaldi Albertini en letra tarzis en Valencia 1304 [9 reales]

[248] Albertí, Arnaldo (1480-1545) ${ }^{67}$

2. Vazquez de sucetione, sin caratula, duplicado en Colonia 1612 [1 peso] [249] Vázquez de Menchaca, Fernando

2. Pedro Cenedo. Colectanea del Derecho Canonico en Zaragoza 1592 [1 peso 4 reales]

[250] Cenedo, Pedro Jerónimo (1540-1603)

2. Luis de Avendaño de Censibus, y sobre las Leyes de Toro en Alcala 1614 [2 pesos]

[251] Velazquez de Avendaño, Luis ${ }^{68}$

2. Pedro Nuñez de Avendaño de secundis um mandatis. Madrid 1793 [2 pesos] [252] Núñez de Avendaño, Pedro

1. Lazaro Riveiro en Leon 1698 [3 pesos]

[253] Riviére, Lazare

1. Juan de Vigo de Zirugia en Madrid 1717 [1 peso]

[254] Vigo, Giovanni da (ca. 1460-post. 1517)

1. Valle controversias medicas en Alcala 1564 [1 peso]

[255] Vallés, Francisco (1524-1592)

1. Altecerra sobre los Decretales. Paris 1666 [1 peso]

[256] Dadin de Hautserre, Antoine (1602-1682)

67 En este registro es evidente que se trata de un error, creemos que se trata de la obra: Clarissimi et perspicacissimi iuris... Arnaldi Albertini... apostolici inquisitoris tunc Maioricen... Impressa Valentie: industria... Francisci Romani..., 1534 (CCPB000156841-8).

68 Como se puede apreciar la segunda obra de este registro no se corresponde con el año de la primera, que suponemos se trata de ésta: Tractatus de censibus Hispaniae: continens librum unum, et centum \& vndecim quaestiones, in quibus materia census per docte explicatur, E omnia iura tam canonica quam regia, E cibilia de censibus loquentia mirifice interpretantur... Compluti: apud Ludouici Martinez Grande: expensis Baptista Lopez..., 1614 (CCPB000806985-9), Legum Taurinarum a Ferdinando E Ioana Hispaniarum regibus foelicis recordationis utilisima glosa sequitur... Toleti: apud Ioannem \& Petrum Rodriguez fratres..., 1588 (CСРB000180350-6). 
1. Tomo trunco de Pandectas Civilis, que es el segundo en Leon 1561 [1 peso 2 reales]

[257] Corpus juris civilis

1. Francisco Verde. Theologia Leon 1672 [3 reales]

[258] Verde, Franciscus, Obispo de Vichy

1. Felix Prospere la gran defensa Mexico 1744 [4 reales]

[259] Prosperi, Félix

1. Paramo de origine inquisitorium en Madrid 1648 [1 peso 2 reales]

[260] Paramo, Luis de

1. Fray Francisco de los Santos. Descripcion del Escorial en Madrid 1698 [4 reales]

[261] Francisco de los Santos (Jer.)

1. Rendina. Promptuario Receptorum trunco en Napoles 1615 [1 peso 4 reales] [262] Rendina, Scipione

1. Padre Vitopliquer sobre el Derecho Canonico en Augusta 1741 [2 pesos 4 reales]

[263] Pichler, Veit (S.I.)

1. Alberto Aldereci de Contratibus en Genova 1678 [1 peso]

[264] Alderisio, Alberto

1. Amidem. De estilo datario Colonia 1741 [1 piso 4 reales]

[265] No se ha identificado

1. Contreras Medula juris. Madrid 1732 [1 peso 4 reales]

[266] Contreras, Antonio de

1. Bocabulario de Nebrija en letra gotica [2 reales]

[267] Antonio de Nebrija (1444-1522) ${ }^{69}$

69 Con estos datos consideramos que la edición podría ser la siguiente: Introductiones latinae. Salmanticae: [Tip. epónima] (16 enero, 1481) CCPB000107690-6. 
1. Ortiz. lugares comunes de la escritura en Alcala 1592 [6 reales] [268] Ortiz Lucio, Francisco (O.F.M.)

1. Peralta Historia de Tovias. Malaga 1667 [1 peso]

[269] Peralta Castañeda, Antonio de

1. Marquez origen de los Padres Hermitaños de San Agustin. Salamanca 1618 [6 reales]

[270] Márquez, Juan (O.S.A.) (1565-1621)

1. Sandobal. Historia de los Reyes de Castilla en Pamplona 1634 [6 reales] [271] Sandoval, Prudencio de

1. Calaorra. Crónica de Siria. Madrid 1684 [1 peso 2 reales]

[272] Calahorra, Juan de (O.F.M.)

1. Delgado Buen rrostro. Historias varias Canonicas en Puebla 1693 [1 peso 6 reales]

[273] Delgado y Buenrostro, Antonio.

1. Morales. Plutarco traducido en Castellano en letra gotica [6 reales] [274] Plutarco $^{70}$

1. Rodrigo Xuarez Español todas las obras en Duacia. 1614 [2 pesos] [275] Rodríguez, Manuel (O.F.M.)

1. Rugineli Comentarios à las constituciones Cesareas en Colonia 1653 [8 pesos]

[276] Ruginellus, Julius Caesar

1. Acosta de Privilegijs creditorum Roma 1661 [2 pesos 1 real] [277] Costa Caldeira, Nuno da

1. Maldonado de secunda suplicatione, obra postuma en Madrid 1690 [1 peso 4 reales]

[278] Maldonado y Pardo, José

70 Consideramos que se trata de esta edición: Morales de Plutarco traduzidos de lengua griega en castellana... Impresso en Alcalá de Henares: por Juan de Brocar, 1548 (CCPB000021354-3). Esta es una edición en letra gótica, como se puede observar en la digitalización que ha realizado la Biblioteca de la Universidad Complutense de Madrid. 
10. Coleccion de Reales Zedulas impresas, y manuscritas con un indice de ellas en Mexico por el Señor Arangoiti 1778 [25 pesos]

[279] Es posible que se trate de un volumen facticio realizado por el propio Oidor.

2. Resumen de Reales Zedulas manuscrito [5 pesos]

[280] Se puede tratar del mismo caso que el anterior.

1. Autos acordados [3 pesos]

[281] Con estos datos es difícil identificar una edición.

\section{Libros en quarto}

2. Mayans. Disputationes juris Leon 1652 [2 pesos]

[282] Mayáns y Siscar, Gregorio (1699-1781)

2. Mesa. Ascendencia de Santo Domingo. trunco. Madrid 1737 [6 reales]

[283] Mesa Benitez de Lugo, Pedro José de (1689-1738)

1. Navarrete. Relacion del agua corriente de Santiago de Queretaro. Mexico 1739 [2 reales]

[284] Navarrete, Francisco Antonio, 1684-1747

1. Melchor de Valencia. Ilustrationes juris. Leon 1563 [4 reales]

[285] Valencia, Melchor de

1. Granuti. Decitiones. Venecia 1585 [4 reales]

[286] Granucci, Paolo (s.16).

1. Amaranta. Speculum aureum. Venecia 1701 [3 reales]

[287] Maranta, Roberto

2. Solis. Arte de servir a Dios. Alcala. 1594 [1 peso]

[288] Solís, Rodrigo de (O.S.A.) (1583)

1. Ferro. Questiones Morales. Leon 1640 [4 reales]

[289] Ferro Manrique, Miguel

1. Juirva. Desitiones. Venecia. 1621 [4 reales] 
1. Amaya observaciones juris. Salamanca 1525 [4 reales]

[291] Amaya, Francisco de

1. Barbosa. Axiomata juris. Ginebra 1651 [3 reales]

[292] Barbosa, Simão Vaz (1591-1681)

1. Gudelini. Comentarios ad jurem en Armenia 1559 [3 reales] [293] Gudelinus, Petrus (1550-1619)

1. Pedro Moliganati. de apelativa verborum. Papiac 1588 [4 reales] [294] Molignati, Giovanni Pietro

3. Mathias Berlichi. Decitiones aurei en Lisia 1695 [1 peso] [295] Berlich, Matthias

1. Wensembec. sobre las Pandectas Leon 1678 [1 peso 4 reales] [296] Wesenbeck, Matthaeus (1531-1586)

1. Misingero. sobre la instituta. sin caratula [4 reales] [297] No se ha identificado

1. Francisco Brueo sobre la instituta Lisia 1622 [6 reales] [298] No se ha identificado

1. Delrrio. Disquisitiones Magicas en Maguncia 1618 [1 peso 2 reales] [299] Delrío, Martín Antonio (S.I.) (1551-1608)

2. Perez Valiente. Aparatus juris Madrid 1751 [1 peso 2 reales] [300] Pérez Valiente, Pedro José

2. Arellano. de jure Chancelaria en Antuerpia 1651 [1 peso] [301] Gómez de Luna y Arellano, Miguel de

2. Gregorio Mayans. de fracmenta cuestante en Genova 1764 [2 pesos 4 reales] [302] Mayáns y Siscar, Gregorio (1699-1781)

1. Michael Mons. sobre la instituta sin caratula [2 reales] [303] No se ha identificado 
4. Geregorij de Mercenfeldt. instituciones imperiales. Colonia 1716 [2 pesos 4 reales]

[304] Merzenfeldt, Gregor

1. Alcaraz. sobre los quatro Juizios en Madrid 1770 [2 pesos] [305] Alcaraz y Castro, Isidoro

1. Cabrera. tripleco seutorum. Madrid 1635 [3 reales]

[306] Cabreros Avendaño, Antonio (n. 1609)

1. Rodriguez explicacion de la Bula. Salamanca 1602 [6 reales]

[307] Rodrigues, Manuel (O.F.M.) (1545-1613)

1. Mercado de Contratos. sin caratula [6 reales]

[308] Mercado, Tomás de (O.P.) ${ }^{71}$

1. Ortega. Gerarquia Ecclesiastica Valladolid 1740 [4 reales]

[309] Ortega Verdecerrense, Francisco Ignacio

1. Retis de Donationibus. sin caratula [2 reales]

[310] Fernández de Retes, Jose ${ }^{72}$

1. Del dicho de interdictis [2 reales]

[311] Fernández de Retes, Jose ${ }^{73}$

1. Mauricio Alcedo. De precedencia Episcopalis en Leon 1630 [3 reales]

[312] Alcedo y Avellaneda, Mauricio de

1. Ripia de testamentos Madrid 1729 [2 reales]

[313] Ripia, Juan de la

1. Padilla. Concilios generales. Madrid 1729 [6 reales]

[314] Padilla, Francisco de

1. Muneta. Distribuciones quotidianas en Milan 1600 [3 reales] [315] Moneta, Alexander 
1. Alvarez de Velasco de legis humana en Leon 1662 [1 peso]

[316] Álvarez de Velasco, Gabriel

1. Narbona de apelatione vicarij ad Episcopum en Toledo 1615 [4 reales] [317] Narbona, Juan

1. Pedro Starmans de jure debolutionis en Bruselas 1677 [3 reales] [318] No se ha identificado

1. Mandoci de imbentionibus 1581 [2 reales]

[319] No se ha identificado

1. Del dicho de comitione ad Beatisimum Papam Venecia 1562 [4 reales] [320] No se ha identificado

1. Simon Celi de Decretis Colonia 1648 [6 reales]

[321] Simoncelli, Ottavio (1620)

1. Naten de Justitia vulnerata. Colonia 1681 [1 peso 2 reales]

[322] Nathen, Stephanus

1. Arellano de juris ratione. sin caratula [2 reales]

[323] Gómez de Luna y Arellano, Miguel ${ }^{74}$

1. Ferro de Prelationibus Ecclesiasticorum en Leon 1635 [2 reales]

[324] Ferro Manrique, Miguel

1. Fray Pedro de los Angeles. Privilegios de regulares. Madrid 1665 [4 reales] [325] Pedro de los Ángeles (O.C.D.)

1. Sebastian Banci. de nulitalibus en Colonia 1716 [1 peso 4 reales] [326] Vantius, Sebastianus

1. Francisco Colon. de Prestatione. Valladolid 1678 [2 reales]

[327] Larriategui y Colón, Francisco de ${ }^{75}$

74 Creemos que se trata de la obra De iuris ratione et rationis imperio... Matriti: typograph. J. Goncalez [sic], 1630 (CCPB000036821-0).

75 La edición localizada tiene pie de imprenta: Pinciae: apud Iosephum Portoles Garcia..., 1678 (CCPB000033938-5). Esta es la forma antigua de Valladolid (Moyano 2006, 141). 
1. Jacobo Estubaco de jure lictoris en Amburgo 1751 [1 peso 4 reales]

[328] No se ha identificado

1. Andres Angulo de mejoras Madrid 1585 [3 reales]

[329] Angulo, Andres

1. Bartolome. Espejo de vusura. Malaga 1698 [4 reales]

[330] Espejo y Cisneros, Bartolomé de, Obispo de Málaga

1. Bargas. Nobleza de España. Madrid 1636 [2 reales]

[331] Moreno de Vargas, Bernabé

1. Compendio del Arte del Padre Carochi en Mexico 1759 [4 reales]

[332] Carochi, Horacio

1. Barbosa. Remitiones Doctorum Valladolid 1621 [3 reales]

[333] Barbosa, Agostinho (1590-1649)

1. Mañer. Antitheatro critico. trunco [3 reales]

[334] Mañer, Salvador José ${ }^{76}$

1. Rolin. Historia antigua trunco [4 reales]

[335] $\operatorname{Rolin}^{77}$

8. Flores España sagrada trunco [4 pesos]

[336] Florez, Henrique

1. Quinto oratio ausum Delfini. Paris 1641 [2 pesos]

[337] Curcio Rufo, Quinto

No se ha identificado

1. Mateuse. de ofizialibus curie Roma 1700 [4 reales]

[338] Matteucci, Agostino (O.F.M.)

76 Creemos que se trata de la obra Antitheatro critico, sobre el primero, y segundo tomo del theatro critico universal del rmo p.m.fr. Benito Feyjoò, maestro general de la religion de s. Benito... En Madrid: se hallarà en casa de Juan de Moya..., 1729 (IT \CCU\CFIE \009319).

77 Con estos datos y tratándose de un autor que suele encontrarse de forma frecuente en este tipo de documentos, consideramos que se trata de esta obra: Historia antigua de los egypcios, cartaginenses, asirios, medos, persas, macedonios, y griegos... traducido a el castellano por Don Joaquin de San Pedro; primer periodo... En Madrid: en la imprenta de Don Antonio Muñoz del Valle: se hallará en la libreria de Juan Yuste, 1768 (CCPB000410422-6). 
1. Galterre. Practica Criminal. Napoles 1609 [2 reales]

[339] Galdieri, Giovanni Paolo (n. 1567)

1. Miranda. de modo procedendi in causas criminales. Salamanca 1601 [4 reales]

[340] Miranda, Luis de (O. F. M.)

1. Dandeudel. Practica Criminal en Antuerpia 1616 [6 reales]

[341] Damhouder, Joost van (1507-1581)

1. Pedro Poleri. Praxis Criminalista. Venecia 1583 [2 reales]

[342] Follerio, Pietro

6. Cevallos la falsa filosofia. Madrid 1764 [8 pesos]

[343] Ceballos, Fernando de (O.S.H.) (1732-1802)

3. Aletin Filaleta. Epistolas del Señor Palafox en Madrid 1773 [3 pesos 4 reales]

[344] Palafox y Mendoza, Juan de ${ }^{78}$

2. Obras sueltas de don Juan de Yriarte (3 pesos)

[345] Iriarte, Juan de

1. Juan Heserr. Lugares comunes del derecho practico en Olanda 1665 (4 reales)

[346] Klenck, Jan (fl. 1648-1669)

1. Guardiola. Titulos de los Grandes de España en Madrid 1541 [3 reales] [347] Guardiola, Juan Benito (O.S.B.) ${ }^{79}$

1. Agustin Caputo de Regimine Reipublice en Napoles 1622 [2 reales] [348] Caputo, Agustin

\section{Ludovico Noni. Medicina. Antuerpia 1644 [4 reales]}

[349] Núñez, Luis (ca. 1555-ca. 1645)

78 En la información de Palau (1990, T. VI, 17), se indica que la obra es de Palafox. Este año se corresponde a la segunda edición, pues la primera es del año anterior. Hemos encontrado la segunda, que es la registrada, con los siguientes datos: Alethini Philaretae epistolarum de venerabilis Johannis Palafoxii Angelopolitani primum, tum Oxomensis Episcopi ortodoxia tomus primus. Mantuae Carpetanorum: [s.n.], 1773 (CCPB000187804-2).

79 Localizamos la edición de 1591, que aparentemente es la más antigua. 
1. Monte Mayor decitiones de cancelaria en Mexico 1667 [2 reales]

[350] Montemayor y Cordoba de Cuenca, Juan Francisco de

1. Velasco arte de predicar. Mexico 1728 [2 reales]

[351] Velasco, Martín de (O.F.M.)

1. Figueroa. el Rey don Pedro defendido en Madrid 1648 ( 2 reales)

[352] Vera y Figueroa, Juan Antonio, Conde de la Roca

1. El Espejo en que se debe mirar el buen Soldado Madrid 1664 [2 reales]

[353] Marquez Cabrera, Juan

1. Diego Gracian. Barzelona 1566 [2 reales]

[354] Onosandro ${ }^{80}$

1. Honrras del Rey Felipe 4o. sin caratula [4 reales]

[355] Calderón, Pedro

1. Gutierrez Curia Pisana Salamanca 1583 [3 reales]

[356] Rodriguez de Pisa, Juan

1. Torres. Cartilla rustica. Madrid 1727 [2 reales]

[357] Torres Villarroel, Diego de (1693-1770)

1. Oliver. Recopilacion de los tumultos de Vngria en Colonia 1587 [4 reales] [358] Oliver y Fullana, Nicolás

1. Oficio del Principe Christiano. Madrid 1624 [4 reales]

[359] Roberto Bellarmino, Santo (1542-1621)

80 La edición que nos parece coincide con este registro es De re militari. Primero volumen. Onosandro Platonico, De las calidades, y partes que ba de tener vn excelente capitan general... Traduzido de griego en castellano, por el secretario Diego Gracian. Segundo volumen. Cesar renouado, que son las obseruaciones militares, ardides, y auisos de guerra, que vso Cesar. Tercero, quarto, y quinto volumen. Disciplina militar y instruction, de los hechos y cosas de guerra de Langeay... En Barcelona: por Claudio Bornat, 1567 (Barcelona: en casa de Claude Bornat impressor y librero, al Aguila fuerte, 1565). IT \ICCU\PUVE \009018. 
1. Guevara. Vida de los Emperadores Romanos sin caratula [3 reales]

[360] Guevara, Antonio de (O.F.M.) (ca. 1481-1545) ${ }^{81}$

1. Francia engañada, y Francia respetada sin caratula [3 reales]

[361] Céspedes y Meneses, Gonzalo de (ca. 1585-1638)

1. Ortiz. Memoria. Entendimiento y Voluntad en Sevila 1677 [4 reales] [362] Ortiz, Lorenzo (S.I.) (1632-1698)

1. Miseno el gran Padre de las gentes Abraban en Madrid. 1546 [4 reales] [363] Niseno, Diego (C.S.B.) (m. 1656) ${ }^{82}$

2. Alfabeto coronado Madrid 1627 [1 peso]

[364] Rojas, Juan de (O. de M.)

1. De dicho trunco [3 reales]

[365] Este mercedario tiene otras siete obras que podrían considerarse.

1. Letras laureadas en Mexico 1794 [2 reales]

[366] Medina (1989) no registra una obra con este título.

1. Escuela de Daniel Madrid 1718 [5 reales]

[367] Miralles Marín, Ginés

1. Fontecha. privilegio para las Mugeres preñadas Alcala 1606 [4 reales]

[368] Alonso de los Ruices de Fontecha, Juan

1. Martinez. Repertorio de los tiempos. sin caratula [6 reales]

[369] Martínez, Enrico (m. 1632)

1. Castro. Fisonomia de la virtud 1666 [3 reales]

[370] Castro, Antonio de (S.I.) (1621-1684)

81 Esta es la obra que se registró: Vidas de los diez emperadores romanos que imperaron en los tiempos de Marco Aurelio... En Madrid: por Mateo de Espinosa: a costa de Gregorio Rodriguez..., 1669 (CCPB000036994-X). El catálogo en donde se ha localizado dice lo siguiente: "Se trata de una coedición que origina la existencia de dos emisiones distintas, con variación en la última línea de la port.: mientras en esta emisión aparece 'a costa de Gregorio Rodriguez...', en la otra 'a costa de Iuan de Calatayud y Montenegro'".

82 Hemos localizado una edición de 1636, en este mismo año existen ediciones en Barcelona y Lisboa y no hemos encontrado ninguna con fecha anterior. 
1. El Sabio en la pobreza. Madrid 1650 [3 reales]

[371] Baños de Velasco y Acevedo, Juan (m. 1682)

1. Villavicencio. Vida de San Pedro Martir en China 1740 [3 reales]

[372] No se ha identificado y Medina (1989), no la registra en su repertorio.

1. Salcedo. Jurisdiccion Real. Madrid 1671 [3 reales]

[373] Gonzalez de Salcedo, Pedro

2. Ribarola. Tratado de la Casa de Borbon [6 reales]

[374] Rivarola y Pineda, Juan Felix Francisco

1. Filateta. Arte de Alquimia. Madrid 1727 [6 reales]

[375] No se ha identificado

1. Clifecio. Vindicta Hispanie Antuerpia 1645 [4 reales]

[376] Chifflet, Jean Jacques (1588-1660)

2. Tesalico olimpico. Sevilla 1733 [1 peso]

[377] Rojo, Juan Bernardino

1. Moreno. Vida del Señor Quiroga. Mexico 1766 [3 reales]

[378] Moreno, Juan José

1. Valiente. Alfabeto Castellano, y otros papeles enquadernados [4 reales] [379] Hipólito Valiente, José ${ }^{83}$

1. Boturini Historia de Nueva España. Madrid 1575 [4 reales]

[380] Boturini Benaduci, Lorenzo (1702-1751) ${ }^{84}$

2. Frafano Bocalini. Madrid 1653 [1 peso]

[381] Boccalini, Traiano (1556-1613)

83 Es posible que se trate de un volumen facticio que contenga un impreso y algunos manuscritos. La edición supone que es: Alfabeto, o nueba qoloqazion de las letras qonocidas en nuestro idioma Qastellano para qonseguir un perfeta qorrespondenzia entre la Esqritura $i$ Pronunziazion dispuesto, por D. Josè Ipolito Baliente, Profesor de Artes enlos Estudios de la Ziudad de Plasenica, i de Leyes en la Unibersidad de Salamanqa. [S.l. : s.n.], 1731 (ССРB000293977-0).

84 En este registro es posible que se haya cometido otro error, pues el autor no había nacido en 1575. Por ello creemos que se trata de la obra: Idea de una nueva historia general de la America septentrional: fundada sobre material copioso de figuras, symbolos, caracteres... En Madrid: en la imprenta de Juan de Zuñiga, 1746 (CCPB000351835-3). 
4. Rolin tratado de Estudios. Madrid 1755 [3 pesos]

[382] Rollin, Charles (1661-1741)

1. Padre Manuel Trinchera. Vida de San Juan de Dios. Madrid 1773 [2 pesos 4 reales]

[383] Trincheria, Manuel (CC.RR.MM.)

1. Vida del Venerable Padre Fray Juan Pecador Madrid 1773 [4 reales] [384] Mascareñas, Jerónimo

1. Reglas de San Agustin en Mexico 1774 [3 reales] [385] Agustinos

2. Valdecebro de Animales. Barzelona. 1696 [1 peso 6 reales] [386] Ferrer de Valdecebro, Andrés (O.P.)

2. Roberto Coni principia juris Talisburgo 1625 [1 peso 4 reales] [387] König, Roberto (1658-1713)

1. Arzipiriqueta Navarro. Reelectiones Leon 1576 [4 reales] [388] Azpilcueta, Martín de (C.R.L.) (1492-1586)

1. Antonio Mathei Cometarios de Crimenes Colonia 1727 [6 reales] [389] Matthaeus, Antonius

1. Salazar. Origen de la renta. Madrid 1746 [3 reales] [390] Salazar de la Cana, Jose

1. Cicateli. Vida de San Camilo Madrid 1743 [1 peso] [391] Cicatelli, Sanzio (M.I.) (1570-1627)

1. Andres Valencis sobre los Decretales Venecia 1745 [1 peso 4 reales] [392] Delvaux, André (1569-1636)

1. Victoria. Relecciones Theologicas. Madrid 1765 [1 peso 6 reales] [393] Vitoria, Francisco de (O.P.) (1483-1546)

1. Gamarra. Elementa Philosofica. Mexico 1774 [3 pesos] [394] Díaz de Gamarra y Dávalos, Juan Benito, 1745-1783 
1. Clausulas de Siguenza. Madrid 1673 [6 reales]

[395] Siguenza, Pedro de

2. Cartas Pastorales del Señor Benedicto catorze. Madrid 1761 [2 pesos]

[396] Iglesia Católica. Papa (1740-1758: Benedicto XIV)

1.Ynstituta de Castilla. Madrid 1771 [2 pesos]

[397] Berni y Catalá, José

1. Elizondo. Practica universa. Madrid 1770 [3 pesos 4 reales]

[398] Elizondo, Francisco Antonio de

1. Coleccion general de las Providencias sobre los regulares de la Compañia. Madrid 1767 [1 peso 4 reales]

[399] Se trata de los documentos legales que se elaboraron para la expuslión de la Compañía de Jesús de los territorios de la Monarquía Española.

3. Castro. Discurso sobre las Leyes Madrid 1765 [3 pesos 4 reales] [400] Castro, Juan Francisco de (1721-1790)

2. Valencia. Ilustrationes juris Salamanca [6 reales] [401] Valencia, Melchor de ${ }^{85}$

33. Vn Legajo con 33 quadernos de varios Autores en 40 [6 pesos 3 reales] [402] Es posible que se trate de impresos menores como sermones u otros.

\section{Libros en octavo}

1. Roderici Xuarez de repeticiones Leon 1553 [2 reales] [403] Suárez, Rodrigo

1. Leonardo Botani en Leon. 1660 [3 reales]

[404] Botallo, Leonardo

\section{Antonio Cruz. de Cirujia. en Lisboa 1683 [2 reales]} [405] Cruz, Antonio da

85 Localizamos la edición D. Melchioris de Valentia... Illustrium iuris tractatuum liber primus... Salmanticae: excudebat Antonia Ramirez viuda, 1625 (CCPB000051967-7). Esta parece ser la más antigua, ya que Palau (1990, T. VII, 100) regista una en Barcelona de 1647, otra en Lyon de 1663 y una más en Ginebra de 1730. 
1. Lamberti. Practica Medica Absterdam 1616 [2 reales]

[406] Massaria, Alessandro (1510-1598)

2. Marin. Principe Catolico. Madrid 1720 [1 peso]

[407] Marín, Juan (S.I.) (1654-1725)

1. Semana Santa en Amberes 1757 [1 peso]

[408] Iglesia Católica ${ }^{86}$

1. Oficio de Nuestra Señora. trunco. Madrid 1762 [2 reales] [409] Iglesia Católica ${ }^{87}$

2. Catecismo historico de Fleuri. Madrid 1750 [1 peso 2 reales]

[410] Fleury, Claude (1640-1723)

1. Lenglé Compendio de la Geografia Paris 1757 [4 reales]

[411] Lenglet du Fresnoy, Nicolas

1. Padre Miguel Diez. El vltimo instante entre la vida y la muerte . Madrid 1763 [1 peso 4 reales]

[412] Diaz, Miguel (S.I.) (1636-1724)

1. Donato Republica de Venecia. Leon 1631 [2 reales]

[413] Giannotti, Donato

2. Coleccion de ordenanzas. Madrid [4 reales]

[414] Ardemans, Teodoro (1664-1726) ${ }^{88}$

86 Creemos que se trata de la obra siguiente aunque la fecha es anterior: Oficio de la semana santa: segun el missal y breviario romano que se publicaron por mandado de su Santidad Pio V y se reconocieron de su Santidad Clemente VIII y Urbano VIII... En Amberes: en la archiemprenta Plantiniana, 1750 (CCPB000855161-8).

87 En este caso la edición localizada es posterior: Oficio de Nuestra Señora la Santisima Virgen Maria: para los tres tiempos del año, con las rubricas en romance. En Madrid: en la Oficina de Antonio Marin, 1768 (CCPB000345022-8).

88 Con estos datos puede complicarse la identificación, por eso creemos que se trata de esta obra: Ordenanzas de Madrid y otras diferentes, que se practican en las ciudades de Toledo y Sevilla, con algunas advertencias à los alarifes y particulares y otros capitulos añadidos á la perfecta inteligencia de la materia que todo se cifra en el govierno politico de las fabricas... En Madrid: por Francisco del Hierro, 1720 (CCPB000391439-9). 
2. Albornos. Cartilla Politica en Madrid [6 reales]

[415] Albornoz, Diego Felipe de ${ }^{89}$

1. Del dicho trunco [2 reales]

[416] Pueden ser cuando menos dos obras diferentes del mismo autor

2. Fuente sucecion Real Madrid 1775 [1 peso 2 reales]

[417] Alvarez de la Fuente, José (O.F.M.)

1. Serra. Historia de Nuestra Señora de Monserrate Barzelona 1742 [6 reales]

[418] Serra y Postius, Pedro (1671-1748)

1. Salgado discurso Cronologico. Mexico 1728 [2 reales]

[419] Vázquez Salgado, Antonio (m. 1750)

1. Branian. Economia de la vida bumana. en Madrid 1759 [2 reales]

[420] Mendez del Yermo, José, trad.

1. Arte de Cozina. Barzelona 1777 [3 reales]

[421] Martínez Montiño, Francisco ${ }^{90}$

1. Vida del Duque de Riperda. Madrid 1740. trunco [2 reales]

[422] Massuet, Pierre (1698-1776)

1. Arriaga. Peregrinacion de Jerusalen. Puerto de Santa Maria [2 reales]

[423] Juan de Santisimo Sacramento (O.F.M.)

1. El Philosofo Sueco Madrid 1747 [2 reales]

[424] Oxenstierna, Axel Gustafsson, Conde de (1583-1654)

1. Historia vniversal del nuevo testamento. Patabia 1759 [4 reales] [425] Biblia $^{91}$

89 Localizamos la edición que Palau (1990, T. I, 32) registra como la primera: Cartilla politica y christiana... En Madrid: por Melchor Sanchez: a costa de Mateo de la Bastida..., 1666 (CCPB000032194-X).

90 Creemos que se trata de esta edición, aunque el año de impresión no se corresponde: Arte de cocina, pasteleria, vizcocheria y conserveria compuesta por Francisco Martinez Montiño. Barcelona: en la imprenta de María Angela Martí viuda..., 1763 (СCPB000226023-9).

91 En esta ciudad sólo hemos encontrado una edición sine data: Historia uniuersa Veteris ac Noui Testamenti in compendium redacta... a Seminarii Patauini alumno; ex gallico in latinum idioma translata ac plurimum aucta; accessere appendices quaedam S. Scripturae studiosis maxime utiles. Patavii: ex typographia Semin[arii] : apud Ioannem [Man]frè..., [s.a.] (CCPB000705558-7). 
3. Ordenanzas Militares Mexico [5 pesos]

[426] Carlos III, Rey de España92

2. Diochesne. Compendio de la Historia de España Madrid 1772 [1 peso 2 reales]

[427] Duchesne, Jean-Baptiste (S.I.) (1682-1755)

1. Comercio de Olanda. Madrid 1746 [2 reales]

[428] Huet, Pierre-Daniel (1630-1721)

3. Nepeu. Reflexiones Christianas. trunco. Barzelona 1757 [1 peso 4 reales] [429] Nepveu, François (S.I.) (1639-1708) $)^{93}$

10. Tomitos truncos de Juan Bautista Pitoni en Venecia 1733 [2 pesos 4 reales] [430] Pitoni, Francesco Maria ${ }^{94}$

1. Roberto Belarmino de oficio Principis en Leon 1619 (2 reales)

[431] Roberto Bellarmino, Santo (1542-1621) ${ }^{95}$

1. Roberto Aureli de rerum judicatarum. Venecia 1599 [1 real]

[432] No se ha identificado

1. Ploto in delitem Venecia 1583 [2 reales]

[433] Piotto, Giovanni Battista

1. Arias Pineli de Consultas. 1514 [2 reales]

[434] Pinhel, Ayres

92 Suponemos que se trata de esta obra: Ordenanzas de S.M. para el regimen, disciplina, subordinacion y servicio de sus exercitos: tomo primero: subdividido en tres tratados... En México: en la imprenta del Br. D. Joseph de Hogal..., [1770] (CCPB000174794-0).

93 La edición consta de cuatro tomos.

94 En este caso se puede tratar de cuando menos dos obras: Francisci Mariae Pitonii aduocati romani deinde Episcopi Romani deinde Episcopi Imeriae, et benedicti XIII Pontif Max Auditoris Disceptationum Ecclesiasticarum in quibus Frequentiora Ecclesiastici Fori Litigia...; Pars secunda. Venetiis: Ex Typographia Balleoniana, 1733 (CCPB000900099-2); y Francisci Mariae Pitonii... Disceptationum ecclesiasticarum: in quibus frequentiora ecclesiastici fori litigia una cum decretis tam Datariae Apostolicae, quam sacrarum congregationum particularium, E generalium, necnon decisionibus Sacrae Rotae Romanae continentur... Pars prima \-IV. Venezia, 1726-1733 $(\mathrm{IT} \backslash \mathrm{ICCU} \backslash \mathrm{RLZE} \backslash 011167)$.

95 Existen dos ediciones en esa ciudad y en la misma fecha. Una de Bernardi Gualteri y otra de Horacio Cardoni. 
1. Sepola de servitutibus. Colonia 1616 [4 reales]

[435] Cipolla, Bartolomeo

1. Reginere. de regalibus en Boenia 1657 [2 reales]

[436] Sixtinus, Regnerus (1543-1617)

1. Burlemaqui. Elementa juris. Venecia 1757 [4 reales]

[437] Burlamaqui, Jean-Jacques (1694-1748)

1. Bigeli sobre la instituta. Lombardia 1643 [3 reales]

[438] Vigel, Nikolaus (1529-1600)

1. Parra. Compendio de la Historia de España Madrid 1734 [3 reales]

[439] Parra, Manuel Juan de la

1. Marton. Antiguedades del Santuario de Zaragoza. Allí 1747 [2 reales]

[440] Martón, León Benito (jer.)

5. Cartas Pastorales del Señor Nuñez de Haro [1 peso 2 reales]

[441] México (Archidiócesis). Arzobispo (Alonso Núñez de Haro y Peralta)

23. Mercurios y Actos en [1 peso 2 reales]

[442] Se trata de un conjunto de impresos menores producidos en la Nueva España. El primer grupo es el Mercurio Volante, publicación del médico José Ignacio Bartolache. El segundo estaría probablemente conformado por las invitaciones a las tesis de la Real y Pontificia Universidad de México.

25. Libros de octavo de medio cada uno [1 peso 4 reales]

[443] Es posible que también se trate de impresos menores de diversa naturaleza, que con esta información no pueden ser identificados.

\section{ANÁLISIS DE LA COLECCIÓN}

El análisis de estos datos nos permite observar cuestiones interesantes. Por ejemplo, que esta biblioteca ni es pobre ni estrictamente devocional, por el contrario la colección que Arangoiti poseía es preponderantemente práctica y útil para un oidor. Es decir, se trata de una biblioteca de trabajo en donde el libro 
es "un bien de consulta, vinculado con profesiones específicas" (Infantes 2006, 168). De ahí que las temáticas no presenten mucha complejidad, pues la gran mayoría de los libros son de derecho canónico, civil, procesal, fiscal e indiano, aunque existan otras disciplinas representadas como se aprecia en la tabla temática siguiente. En esta biblioteca de jurisprudencia, al igual que otras semejantes (Barrio 2008, 857), se encontraban autores muy reconocidos en el Derecho como Andrea Tiraqueau (31), Jerónimo Castillo de Bovadilla (94), Gregorio López (87), Juan de la Ripia (313) Antonio Gómez (43), Andrés Mendo (26), Gabriel Pareja y Quesada (27), Antonio Diana (28, 29 y 54), Juan del Castillo Sotomayor (34), Francesco Negri (36), Giuseppe Mascardi (48), Juan Solórzano Pereira (59), Hevia Bolaño (106), Manuel González Téllez (62) o Pedro Barbosa (176), entre otros. Evidentemente no faltan las compilaciones, adiciones y comentarios tan necesarios para los abogados y que están presentes en las bibliotecas de esa época (Fernández 1999-2000, 107-160).

\begin{tabular}{|l|c|}
\hline \multicolumn{1}{|c|}{ Tema } & Porcentaje \\
\hline Derecho & 72 \\
\hline Historia & 10 \\
\hline Teología & 1 \\
\hline Doctrina Cristiana & 1 \\
\hline Filosofía & 1 \\
\hline Literatura & 3 \\
\hline Arte y ciencias militares & 1 \\
\hline Hagiografías & 5 \\
\hline Ciencias & 3 \\
\hline Otros & 3 \\
\hline
\end{tabular}

Tal característica temática nos permite mirar con atención a los libros que no pertenecen a tan ilustre conjunto. Empecemos por los históricos que abarcan diversos asuntos como la historia del padre Mariana (125), la Historia de África (208), la Crónica de Siria (272), la de la Casa Farnesio (216), la de Felipe de Comines (224), Crónicas religiosas como la de los misioneros en Filipinas (213) o de la Orden de Santiago (237), la descripción del Escorial (261), y varios más que muestran un claro interés por este tipo de libros. En los devocionales se trata especialmente de vidas de santos como San Francisco Borja (225), San Juan de Dios (383), San Camilo (391) o San Pedro Mártir (372) pero también se incluyen otras cosas como el Oficio de la Semana Santa (408) o cartas pastorales (306 y 441) entre otros temas interesantes que se relacionan con los libros de teología, doctrina cristiana y filosofía. Aunque en este último tema hay un libro que podría pasar por luterano y me refiero al "Filósofo y luterano desengañado" (424). 
Sin duda, esta biblioteca profesional también habla de intereses muy personales, que se aprecian muy bien en tres temáticas concretas: Literatura, Ciencias y las Artes Militares. En la primera veremos representados a clásicos como Plutarco (274) y Séneca (371), al vocabulario de Nebrija (267), que podría haber sido lo que hoy consideramos un incunable pues esta obra con la característica de "letra gótica" parece ser la impresa en Salamanca en 1481. Encontramos un arte de lengua náhuatl como la de Carochi (332) o para el estudio de la lengua francesa como el de Rolin (382). Quizá en este grupo el más interesante sea el manual de escritura de Hipólito Valiente (379). La segunda temática muestra libros bastante curiosos como un Atlas (235) cuya edición no hemos podido localizar y que fue de los libros más caros en la tasación (con 12 pesos), otro relacionado con la Geografía aunque pareciera más didáctico (411), uno de ingeniería dedicado al agua corriente en su lugar de residencia y muerte, Querétaro (284).

Hay también bastantes libros de medicina como el de las mujeres preñadas (368), el de cirugía de Antonio Cruz (405), el de práctica médica de Massaria (406), o el de Luis de Núñez (349). Aunque parezcan extraños los libros médicos en la biblioteca de un abogado, lo cierto es que ya se ha mostrado que otros oidores también tenían este tipo de literatura (Fernández 1999-2000, 111), pero hasta no construir tendencias más claras con el estudio de estos documentos y la comparación de la información obtenida, no podremos saber si se trataba de intereses personales o de libros que también eran útiles para la práctica profesional de los oidores.

Para cerrar este conjunto hay que decir que incluso Arangoiti tenía un libro sobre animales, el de Valdecebro (386) y que podríamos considerar que estaba interesado en el conocimiento científico, como lo testimonia su colección del Mercurio Volante (441). Esta fue una publicación que podríamos denominar de divulgación científica y fue publicada por el ilustrado José Antonio Bartolache en la Nueva España entre 1772 y 1773 e impreso por Felipe de Zúñiga y Ontiveros. La colección estaba acompañada por "Actos", que podrían tratarse de las invitaciones a las titulaciones universitarias o las tesis mismas. Un asunto que no termina de dilucidarse del todo y que requiere de un estudio. Sin duda, lo que sí sabemos es que estos resultaban un producto rentable para los impresores novohispanos, porque en los inventarios de sus prensas suele encontrarse material gráfico para estos objetos. Finalmente hay que destacar un Arte de Cocina (420), cuestión notoria pues como vimos Arangoiti tuvo cocinera y al parecer en gran estima. Por tal razón es pertinente recordar que la posesión de un libro no significa su inevitable lectura, por eso debemos ser muy cuidadosos en equiparar los libros en circulación en un periodo específico con los libros leídos o con los lectores. 
En cuanto al tipo de materiales la biblioteca contuvo solamente tres manuscritos y un incunable, el restante son impresos en su mayoría producidos entre los siglos XVI y XVII, como se puede apreciar en la gráfica. Por esa razón y pese a su riqueza esta biblioteca no puede ser considerada formalmente como ilustrada, pues no se aprecia el incremento notable de obras publicadas desde la segunda mitad del siglo XVII y las publicadas durante el siglo XVIII (Bas 1998, 126). Especialmente considerando que Arangoiti muere a finales del periodo de la Ilustración.

Esta es la cuestión que nos parece más importante de destacar pues muestra la vitalidad del mercado del libro usado, un tipo de compra que abarataría sensiblemente la adquisición de los lectores. Pero debemos considerar que en el inventario existen varios registros en donde parece haber un error al anotar las fechas. Así un solo número cambia completamente la fecha, por ejemplo 1688 por 1678 (79), 1544 por 1594 (202), o 1583 por 1593 (356). Estos errores, algunos muy evidentes, podríamos atribuirlos a Ignacio Quesada, quien fue la persona encargada de copiar los inventarios en limpio. Por otro lado encontramos registros que consignan ediciones con uno o dos años de diferencia de la fecha que fue anotada en el inventario (véase 17, 165, 285, o 387, por citar algunos casos). Asimismo encontramos ediciones conservadas que tienen varios años de diferencia con los datos del documento histórico (117 o 219$)$.

Consideramos importante distinguir la presencia de libros novohispanos, que como habíamos anotado podrían confirmar la idea de que esa producción fue hecha principalmente para un mercado local. Lo que no denotan estos impresos es un interés más enfocado a los contenidos temáticos americanos como la tendencia ha mostrado en las bibliotecas de los funcionarios coloniales del siglo XVIII (Rueda 2007, 204).

\begin{tabular}{|l|r|}
\hline \multicolumn{1}{|c|}{ Fecha } \\
\hline Sin año & 17 \\
\hline Siglo XV & 1 \\
\hline Siglo XVI & 66 \\
\hline Siglo XVII & 193 \\
\hline Siglo XVIII & 156 \\
\hline Total & 433 \\
\hline
\end{tabular}

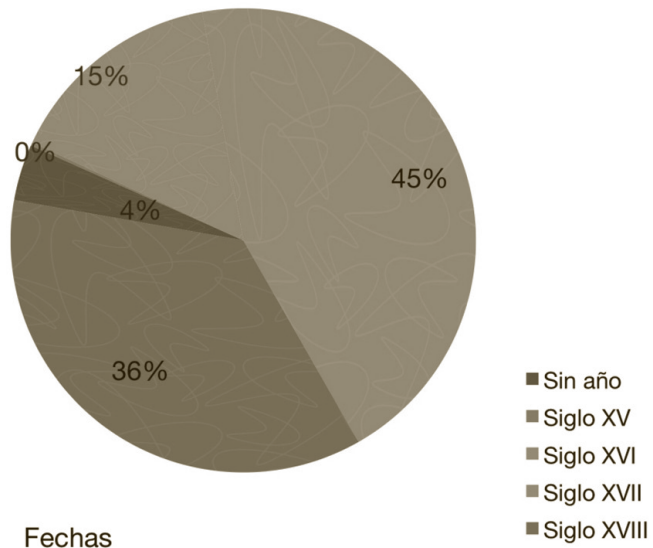


Por otro lado, gracias a la precisión del avalúo de Cueto sabemos que el $31 \%$ de los libros fueron producidos en Madrid y Lyon, aunque veremos representadas importantes ciudades de producción impresa tales como Venecia, Salamanca, Barcelona, Amberes, París, Lisboa, Basilea, México y otras más. La proporción del número de libros puede observarse en la gráfica siguiente, auque debemos aclarar que las ciudades se han mezclado en un apartado único por el número de registros que comparten:

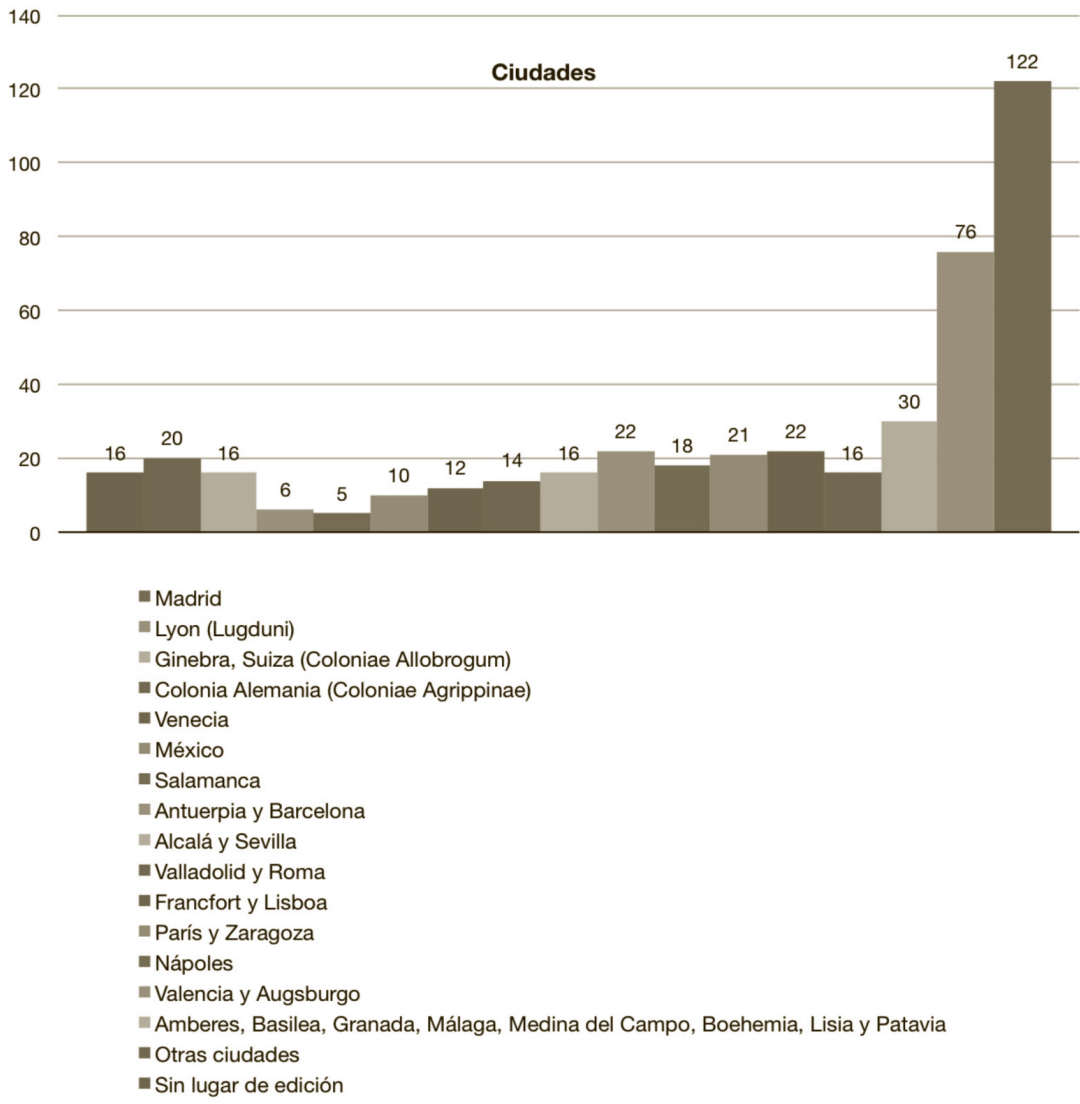

Ahora bien, queda mencionar aquí el aspecto más olvidado en la historia de las bibliotecas: los precios del libro. No olvidemos que el libro antiguo estaba sujeto a un precio controlado por la Monarquía, denominado "tasa". Este precio se establecía sobre el número de pliegos que se habían empleado en la producción "sin principios ni finales" y en rama; es decir, sin encuadernar. Lo que significaba que no se consideraba en la tasación al cuaderno de los preliminares, que contenía principalmente los documentos legales de 
la edición. Lamentablemente el documento de Arangoiti no incluye ninguna apreciacion sobre el estado en que se encontraban los materiales o el tipo de encuadernación que poseían, información que podemos encontrar en otros testimonios de bibliotecas. Este dato resulta relevante porque, en ciertos casos, esas características afectaban la tasación, pues el material muy deteriorado era valuado a la baja o ni siquiera era considerado para establecer un costo (v. gr. "nada").

Por eso, con la información disponible sobre el precio podemos suponer que el material aunque era viejo no estaba demasiado deteriorado, ya que un poco menos de la mitad de los libros fueron tasados entre un peso (11\%), cuatro reales $(10 \%)$, dos reales $(9 \%)$, seis reales $(8 \%)$ y tres reales $(7 \%)$. Es decir, un precio razonablemente accesible para aquellos con suficiente solvencia económica e interesados en los libros. Por el contrario otros libros, ciertamente pocos, fueron altamente valorados llegando a alcanzar los cuarenta y cinco pesos: como los seis tomos del Diccionario de la Lengua Española (51). Otros como las obras de Agustín Barbosa se tasaron en treinta pesos (98), ${ }^{96}$ y en veinticinco las de Rodríguez Hermosino (236) y el volumen manuscrito de las reales cédulas (279). Fue alto el costo que se otorgó al manuscrito de Arangoiti, como se puede comprobar del mismo dinero que él mandó entregar a quienes trabajaron en su casa, como hemos visto. Las tendencias generales pueden observarse en la siguiente gráfica. 

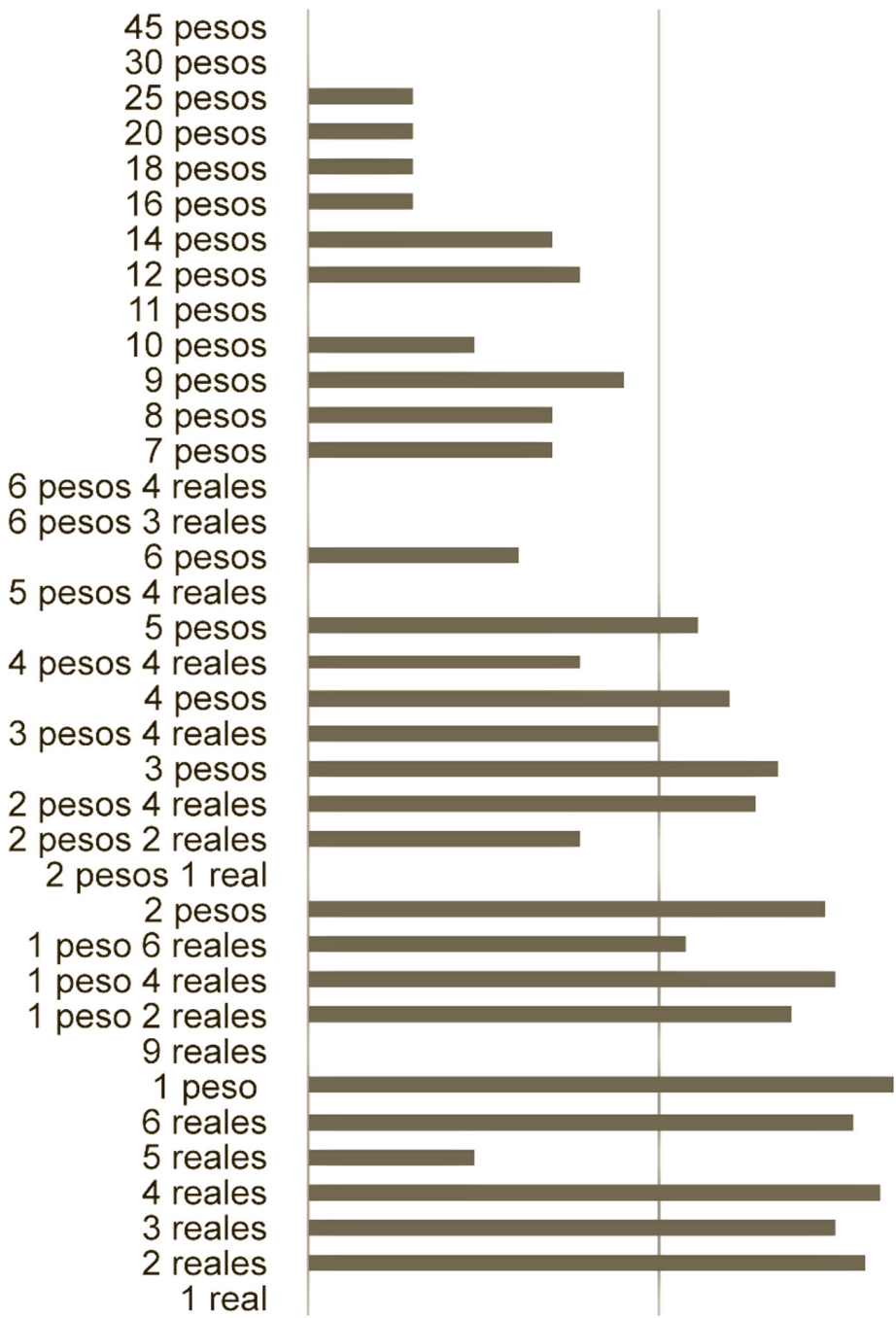

10

Estos datos, en tanto podamos comparar varios inventarios, podrán tener una buena utilidad para el conocimiento de las bibliotecas del pasado y para contribuir tanto al estudio de la cultura escrita como a la valoración del legado bibliográfico. Tal cotejo nos permitiría por un lado identificar con mayor precisión las obras y ediciones registradas, también poder analizar tendencias en los registros de una época y así comprender cómo se apuntaban principalmente 
los autores. Por ejemplo, Simón Celi por Simoncelli (321), ${ }^{97}$ Banci por Vantius (326), Poleri por Follerio (342), etc. Forma que también afectaba al registro de las obras. Dilucidar estas formas culturales del registro como una forma de representación nos permitirá identificar mejor las obras, y así determinar si algunas de las ediciones han desaparecido por más terrible que nos parezca. Esta es una realidad ineludible: un importante conjunto de las ediciones del pasado se han destruido por numerosas razones, intencionales o no.

Lo mismo ocurrirá con los precios y podremos determinar con certeza por qué y bajo qué consideración algunos libros aumentan, reducen o mantienen un precio estable en el mercado. Por ejemplo, en 1764 la edición de 1763 de la "Historia de la imperial, nobilissima, inclita y esclarecida ciudad de Toledo" fue tasada en dos pesos (García y Montiel 2010, 70). En este avalúo de 1780, la edición del siglo XVIII de la misma obra (219) y que no localizamos fue tasada en tan sólo 6 reales. Es decir, un precio comparativamente menor. También debemos precisar el costo de otros objetos según la información de los inventarios post mortem, para entender con mayor claridad y en comparación a qué otras cosas un libro podía o no ser caro.

Por ejemplo, Arangoiti poseía un elegante par de mancuernas de plata y piedras que fueron tasados en dos pesos. ${ }^{98}$ Con ese mismo dinero una persona interesada podría comprarse varias obras jurídicas que constituyeron el basamento de la cultura de los abogados de su tiempo como las obras de Julio Claro (4), la obra de Villadiego (109) pero también las cartas pastorales del papa Benedicto XIV (396), entre otros libros. Los datos analizados y comparados muestran la posibilidad de que bibliotecas como la de Arangoiti se hayan constituido con una parte de los libros de otros difuntos. Pero esta es una interpretación que podremos corroborar o descartar sólo con más recuperación, transcripción y análisis de datos. Una tarea que requiere paciencia y tiempo.

97 Octavii Simoncelli... Tractatus de Decretis ceterisque solemnitatibus in contractibus minorum, pupillorum, aliorumve bis similium adbibendis... Index item titulorum... cura E studio Antonii Kappelii... Editio Novissima diligenter revisa \& ab innumeris erroribus purgata. Coloniae Agrippinae: Typis \& sumptibus Francisci Metternich, 1698 (CCPB000136839-7).

98 AGN, Intestados, Vol. 48, exp. 2, fol.329r. 
Arnold, Linda (1980), Directorio de burócratas en la Ciudad de México, 1761-1832. México: Archivo General de la Nación (Guías y catálogos; 52)

Barrio Moya, José Luis (2008), “La biblioteca Jurídica de D. Antonio Rama Palomino y Ozerín, abogado de los Reales Consejos (1750)", Anuario Jurídico y económico escurialense, núm. 41, pp. 851-864. Texto disponible en http://www.rcumariacristina.com/ ficheros/VI\%20JOSE\%20LUIS\%20BARRIO.pdf [Consulta: noviembre de 2011]

, (2004), "Una interesante biblioteca jurídica madrileña del siglo XVII y otros bienes de don Cristóbal de Corcos, abogado de los Reales Consejos (1639), Anuario jurídico y económico escurialense, núm. 37, pp. 839-851. Texto disponible en http://www.rcumariacristina.com/ficheros/varia_06.pdf [Consulta: octubre 2011]

Barrio Moya, José Luis (2000), "La librería del abogado riojano Don Diego de Castroviejo, relator del Consejo de Guerra durante el reinado de Felipe V", Militaria: revista de cultura militar, núm. 14, pp. 137-145. Texto disponible en http://revistas.ucm.es/index.php/MILT/article/ viewFile/MILT0000110137A/3332 [Consulta: octubre de 2011]

Bas Martín, Nicolás (1998), "Una aproximación a la biblioteca del ilustrado valenciano Juan Bautista Muñoz (1745-1799)", Saitabi: revista de la Facultad de Geografía i Història, Núm. 48, pp. 113-147.

Bass, Stephen T. (2008), Basques in the Americas From 1492 to 1850: A Chronology. September. Texto disponible en http://nabasque.org/ pdf/Basque_Chronology_2008_09.pdf [Consulta: septiembre 2011]

Borah, Woodrow Wilson (1983), Justice by insurance: the General Indian Court of Colonial Mexico and the Legal Aides of the Half-Real. Berkeley: University of California Press.

Brading, David Anthony (1983), Mineros y comerciantes en el México Borbónico, 1763-1810. México: FCE.

Burkholder, Mark y D.S. Chandler (1982), Biographical Dictionary of Audiencia Minister in the Americas, 1687-1821. Westport, Connecticut: Greenwood Press.

Chandler, D.S. (1991), Social Assistance and Bureaucratic Politics: The Montepios of Colonial Mexico, 1767-1821. Albuquerque: University of New Mexico Press.

Dadson, Trevor (2008), "Las bibliotecas de la Nobleza: dos inventarios y un librero, año de 1625 ", en Mecenazgo y bumanidades en tiempo de Lastanosa: Homenaje a Domingo Ynduraín, coord. Aurora Gloria Elgido Martínez y José Enrique Laplana Gil. Zaragoza, España: Institución Fernando el Católico: Instituto de Estudios Altoaragoneses, pp. 253-302. Texto disponible en http://ifc.dpz. es/recursos/publicaciones/28/57/12dadson.pdf [Consulta: septiembre de 2011] 
Fernández Sotelo, Diego (1999-2000), "Biblioteca del oidor de la Audiencia de la Nueva Galicia Joseph Manuel de la Garza Falcón (1763)", Anuario Mexicano de Historia del Derecho, Volumen XIXII, pp. 91-160. Texto en consulta en http://www.juridicas.unam. $\mathrm{mx} / \mathrm{publica} / \mathrm{librev} / \mathrm{rev} / \mathrm{hisder} / \mathrm{cont} / 11 / \mathrm{cnt} / \mathrm{cnt} 5 . \mathrm{pdf}$ [Consulta: noviembre de 2011]

García, Idalia (2010), "Suma de bibliotecas novohispanas: hacia un estado de la investigación”, en Leer en tiempos de la Colonia: imprenta, bibliotecas y lectores en la Nueva España, compiladores Idalia García y Pedro Rueda Ramírez. México: CUIB, 2010, pp. 281-307.

García, Idalia y Ana Cecilia Montiel (2010), "Una vida entre cajones de libros: Felipe Pérez del Campo en la Nueva España” en colaboración con Ana Cecilia Montiel Ontiveros, Estudios de Historia Novohispana, vol. 43 (julio-diciembre), pp. 51-107. Texto disponible en http://www.historicas.unam.mx/publicaciones/revistas/ novohispana/pdf/novo43/523.pdf [Consulta: noviembre de 2011]

Gates, Eunice Joiner (1928), "Don José Antonio de Areche: His Own Defense", The Hispanic American Historical Review, Vol. 8, No. 1 (Feb., 1928), pp. 14-42.

Huarte Morton, Fernando (1955), "Las bibliotecas particulares españolas de la Edad Moderna”, Revista de Archivos, Bibliotecas y Museos, Tomo 61, núm. 1-2, pp. 555-576.

Infantes de Miguel, Víctor (2006), Del libro áureo. Madrid: Calambur. Lamarca Langa, Genaro (1994), La cultura del libro en la época de la Ilustración. Valencia, 1740-1808. Valencia: Edicion Alfons el Magnànim.

López Fando, José Manuel (1798), Prontuario de testamentos y contratos, obra útil no solamente a los escribanos principantes... Tomo Primero. Madrid: en la Imprenta de D. Benito Cano.

Medina, José Toribio (1989), La imprenta en México (1539-1821). México: UNAM, 8 volúmenes.

Moyano Andrés, Isabel (2006), Toponomástica. Madrid: Arco Libros.

Palau y Dulcet, Antonio (1990), Manual del librero hispano-americano: Inventario bibliográfico de la producción científica y literaria de España y de la América Latina desde la invención de la imprenta hasta nuestros días, con el valor comercial de todos los artículos descritos. Madrid: Juan Ollero Editor, 7 tomos.

Pelegrí Pedrosa, Luis Vicente (2003), "Riquezas del clero indiano en el siglo XVII a través de los Autos de Bienes de Difuntos", Temas Americanistas, núm. 16, pp. 16-28. Texto disponible en http://institucional.us.es/tamericanistas/uploads/revista/16/PELEGRI.pdf [Consulta: octubre de 2011]

Ramírez González, Clara Inés (2002), “Testamento e inventario de los bienes del doctor Hernando Ortiz de Hinojosa, 1598”, en su libro Grupos de poder clerical en las Universidades Hispánicas II. México, UNAM. Centro de Estudios sobre la Universidad, pp. 317-348. 
Ripia, Juan de la (1718), Practica de testamentos y modos de suceder... Con licencia en Madrid: En la Imprenta de Ángel Pascual.

Rodríguez Álvarez, María de los Ángeles (2001), Usos y costumbres funerarias en la Nueva España. Zamora, Michoacán: El Colegio de Michoacán: El Colegio Mexiquense.

Rueda Ramírez, Pedro (2007), "La biblioteca americanista de Dionisio de Alcedo y Herrera, presidente de la Real Audiencia de Panamá, en 1742", Colonial Latin American Historical Review, vol. 16, núm. 2, pp. 197-224.

Sanciñena Asurmendi, Teresa (1999), La audiencia de México en el reinado de Carlos III. México: UNAM. Instituto de Investigaciones Jurídicas. Texto disponible en http://biblio.juridicas.unam.mx/libros/1/108/3.pdf [Consulta: noviembre de 2011]

Sobrado Correa, Hortensio (2003), "Los inventarios post-mortem como fuente privilegiada para el estudio de la historia de la cultura material en la Edad Moderna”, Hispania, vol. 63, núm. 215, pp. 825-861. Texto disponible en http://hispania.revistas.csic.es/index.php/hispania/article/view/207/210 [Consulta: octubre 2011]

Torales Pacheco, Josefina María Cristina (2001), Ilustrados en la Nueva España: los socios de la Real Sociedad Bascongada de los Amigos del País. México: Real Sociedad Bascongada de los Amigos del País: Colegio de San Ignacio de Loyola Vizcaínas: Universidad Iberoamericana.

Torre Revello, José (1962), "Lecturas indianas, siglos XVI-XVIII", Thesaurus. Boletín del Instituto Caro y Cuervo, Tomo 17, núm. 1, pp. 129. Texto disponible en http://cvc.cervantes.es/lengua/thesaurus/ pdf/17/TH_17_001_001_1.pdf [Consulta: noviembre de 2011]

Wanderley, Marcelo (2000), "Si Saben Ustedes de los Méritos. Escritura, Carreras de Abogados y Redes Personales en la Nueva España (1590-1700)", Anais Eletrônicos do V Encontro da ANPHLAC, pp. 1-59. Texto disponible en http://anphlac.org/upload/anais/encontro5/marcelo_wanderley.pdf [Consulta: abril 2012] 